\title{
Circumventing furin enhances factor VIII biological activity and ameliorates bleeding phenotypes in hemophilia models
}

\author{
Joshua I. Siner, ${ }^{1}$ Benjamin J. Samelson-Jones, ${ }^{1,2}$ Julie M. Crudele, ${ }^{1,2}$ Robert A. French, ${ }^{1,2}$ \\ Benjamin J. Lee, ${ }^{1}$ Shanzhen Zhou, ${ }^{1}$ Elizabeth Merricks, ${ }^{3}$ Robin Raymer, ${ }^{3}$ Timothy C. Nichols, ${ }^{3}$ \\ Rodney M. Camire, ${ }^{1,2}$ and Valder R. Arruda ${ }^{1,2}$ \\ 'The Children's Hospital of Philadelphia, Philadelphia, Pennsylvania, USA. Perelman School of Medicine, University of \\ Pennsylvania, Philadelphia, Pennsylvania, USA. ${ }^{3}$ University of North Carolina, Chapel Hill, North Carolina, USA.
}

\begin{abstract}
Processing by the proprotein convertase furin is believed to be critical for the biological activity of multiple proteins involved in hemostasis, including coagulation factor VIII (FVIII). This belief prompted the retention of the furin recognition motif (amino acids 1645-1648) in the design of B-domain-deleted FVIII (FVIII-BDD) products in current clinical use and in the drug development pipeline, as well as in experimental FVIII gene therapy strategies. Here, we report that processing by furin is in fact deleterious to FVIII-BDD secretion and procoagulant activity. Inhibition of furin increases the secretion and decreases the intracellular retention of FVIII-BDD protein in mammalian cells. Our new variant (FVIII- $\Delta F$ ), in which this recognition motif is removed, efficiently circumvents furin. $F$ III- $\Delta F$ demonstrates increased recombinant protein yields, enhanced clotting activity, and higher circulating FVIII levels after adeno-associated viral vector-based liver gene therapy in a murine model of severe hemophilia A (HA) compared with FVIII-BDD. Moreover, we observed an amelioration of the bleeding phenotype in severe HA dogs with sustained therapeutic FVIII levels after $F$ VIII- $\Delta F$ gene therapy at a lower vector dose than previously employed in this model. The immunogenicity of FVIII- $\Delta F$ did not differ from that of FVIII-BDD as a protein or a gene therapeutic. Thus, contrary to previous suppositions, FVIII variants that can avoid furin processing are likely to have enhanced translational potential for HA therapy.
\end{abstract}

Authorship note: J.I. Siner and B.J. Samelson-Jones contributed equally to this work.

Conflict of interest: R.M. Camire and V.R. Arruda hold patent rights (patent number 8,816,054) for enhancing FVIII coagulation function. R.M. Camire receives research support from Pfizer and Novo Nordisk. V.R. Arruda receives research support from Pfizer. B.J. Samelson-Jones receives grant support from Bayer and Novo Nordisk.

Submitted: July 5, 2016

Accepted: August 30, 2016

Published: October 6, 2016

Reference information:

JCI Insight. 2016;1(16):e89371.

doi:10.1172/jci.insight.89371.

\section{Introduction}

Hemophilia A (HA) is a common inherited severe bleeding disorder. It is an X-linked disease affecting about 1 in 5,000 male births and is due to deficiencies in coagulation factor VIII (FVIII) activity arising from mutations in the $F 8$ gene. Medical management focuses on replacing the missing FVIII activity by intravenous administration of either plasma-derived or recombinant FVIII protein. However, the high cost of factor replacement currently restricts this treatment to only about $20 \%$ of patients, mostly in developed countries. Recent clinical trial success of adeno-associated viral (AAV) vector liver-directed gene therapy of factor IX (FIX) for hemophilia B (HB) engenders optimism that FVIII gene therapeutics may be efficacious for HA $(1,2)$. However, biological differences between FVIII and FIX produce specific obstacles for FVIII gene transfer that impede the direct adoption of successful strategies of FIX gene transfer for HA (3). Preclinical studies in HA murine and canine models suggest that higher vector doses will likely be required to achieve comparable factor levels as have been attained in HB studies (4-6). New technologies are urgently needed to reduce the cost of FVIII production to extend factor replacement therapy to the $80 \%$ of worldwide patients currently not receiving treatment as well as to enhance the efficiency of FVIII gene transfer in order for gene therapy for HA to be a clinical possibility.

The biology of FVIII is, therefore, of considerable scientific and clinical interest (7-10). FVIII is synthesized as a single-chain (SC) polypeptide with a domain structure of A1-A2-B-A3-C1-C2, but circulates in plasma bound to von Willebrand factor (VWF) as mostly a heterodimer composed of a heavy chain (HC) and light chain (LC) consisting of A1-A2-B and A3-C1-C2, respectively (8). The formation of the heterodimer is primarily due to proteolytic cleavage by the proprotein convertase furin (PACE/ furin) within the B-domain at either R-1313 and/or R-1648 (11, 12), with both sites satisfying the minimal 
Table 1. Short peptide linkers substituted for the B-domain in factor VIII variants

\begin{tabular}{|c|c|c|c|c|}
\hline Commercial Examples & Variant Name & Length (aa) & (741)-Linker Sequence-(1649) ${ }^{A}$ & Ref \\
\hline Xyntha, Eloctate & hFVIII-SQB & 14 & SFSQNPPVLKRHQR & (12) \\
\hline NovoEight, N8 GP & hFVIII-N8 & 21 & SFSQNSRHPSQNPPVLKRHQR & (27) \\
\hline Nuwiq & h-cl rhFVIII & 16 & SFSQNSRHQAYRYRRG & (29) \\
\hline NA & hFVIII-V3 & 31 & SFSQNATNVSNNSNTSNDSNVSPPVLKRHQR & (28) \\
\hline NA & hFVIII-RH & 14 & SFSQNPPVLKHHQR & (34) \\
\hline NA & cFVIII-HR & 14 & SFSQNPPVSKRHQR & this report \\
\hline NA & $c F V I I I-\Delta F$ & 10 & SFSQNPPVSK & this report \\
\hline
\end{tabular}

${ }^{A}$ Furin recognition motif underlined. ${ }^{B}$ Also referred to as hFVIII-BDD in text and literature. aa, amino acids; cFVIII, canine factor VIII; hFVIII, human FVIII; h-cl rhFVIII, human cell line-derived recombinant human FVIII; NA, not applicable; pFVIII, porcine FVIII;

recognition motif of furin, $\mathrm{R}-\mathrm{X}-\mathrm{X}-\mathrm{R} \downarrow$ (where $\mathrm{X}$ represents most amino acids and $\downarrow$ the cleavage position) $(13,14)$. Furin is a serine protease responsible for the intracellular cleavage and processing of myriad proteins that contribute to health as well as to neoplastic, autoimmune, inflammatory, and infectious diseases $(13,14)$. Cleavage by furin is also required for the biological activity of a number of proteins needed for hemostasis including factor VII (FVII), FIX, protein C, protein S, and vWF (13, 15-17). Recombinant expression systems for commercial FIX products have relied on cotransfection with furin to enhance production of biologically active protein $(18,19)$.

In plasma, there is a heterogeneous population of FVIII species with variable C-terminal proteolysis of the B-domain (7) that all have similar biological activities (20). Recombinant human FVIII variants with most or all of the B-domain deleted have similar clotting activity; however, they also have been found to have substantially higher expression levels compared with full-length FVIII $(12,21,22)$. These attributes led to such variants being successfully developed over the last 2 decades as protein replacement therapy, which has demonstrated equivalent safety, efficacy, and pharmacokinetics to that of full-length recombinant FVIII (23-25). Additionally, B-domain-deleted FVIII (FVIII-BDD) has been utilized in multiple vector systems for gene therapy studies because of its smaller size and enhanced expression (3).

In the design of FVIII-BDD (also known as FVIII-SQ), 14 amino acids of the B-domain, including the furin recognition site from 1645-1648 (Table 1), were retained to link the HC and LC and allow for appropriate intracellular processing by furin $(12,23,26)$. Comparable linkers containing this furin recognition motif have frequently been used in the development of novel HA therapies (27-29) as well as expression systems for orthologous FVIII constructs (30-33), even though the role of furin in FVIII biology remains undefined. We have recently reported that a single amino acid substitution $(\mathrm{R} 1645 \mathrm{H})$ within the furin recognition site of human FVIII-BDD (hFVIII-BDD) results in a FVIII variant with enhanced expression and increased clotting activity (34). The design of this variant was based on our earlier observations that (a) canine FVIII-BDD (cFVIII-BDD) has higher biological activity than hFVIII-BDD (30), (b) cFVIII-BDD is secreted primarily as the SC species (30), and (c) histidine is at position 1645 in cFVIII, which is surprising since most furin recognition motifs contain arginine at this position (34). The R1645H substitution in our variant was hypothesized to impede the interaction between FVIII and furin (34). These results motivated us to undertake a more complete investigation of the role of furin in FVIII biology. Herein, we found that furin processing actually has a deleterious effect on both FVIII secretion and its clotting activity, which is contrary to the role of furin in processing other hemostatic proteins and opposite previous suppositions about FVIII. Moreover, a new FVIII variant (FVIII- $\Delta$ F) that avoids intracellular furin processing demonstrates enhanced efficiency of AAV-based liver-directed gene therapy in a preclinical large-animal model of HA without increasing the immunogenicity.

\section{Results}

To determine the role of furin processing in FVIII biology, we carried out a series of in vitro experiments in which the interaction between furin and FVIII was purposely abrogated using either a furin-deficient cell 


\section{hFVIII-BDD:}
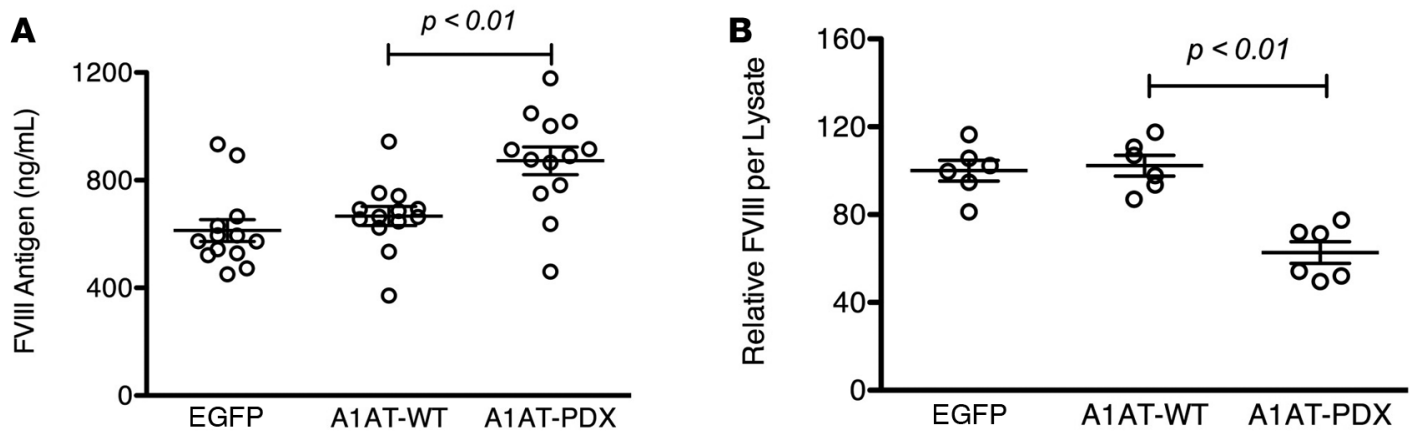

\section{$\underline{\mathrm{hFVIII}-\Delta \mathrm{F}:}$}
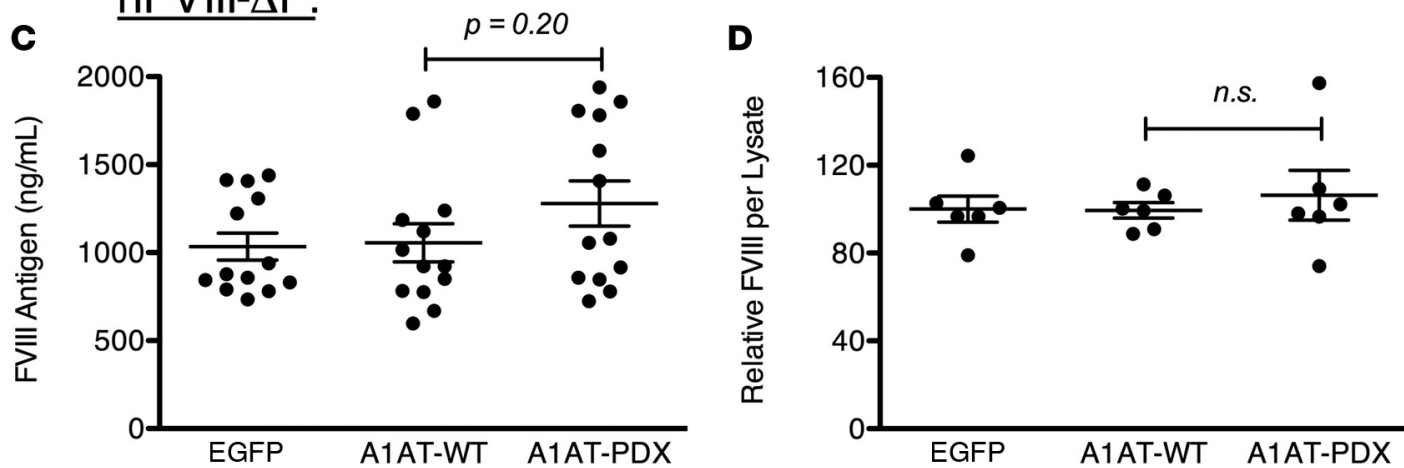

\section{$\mathbf{E}$}

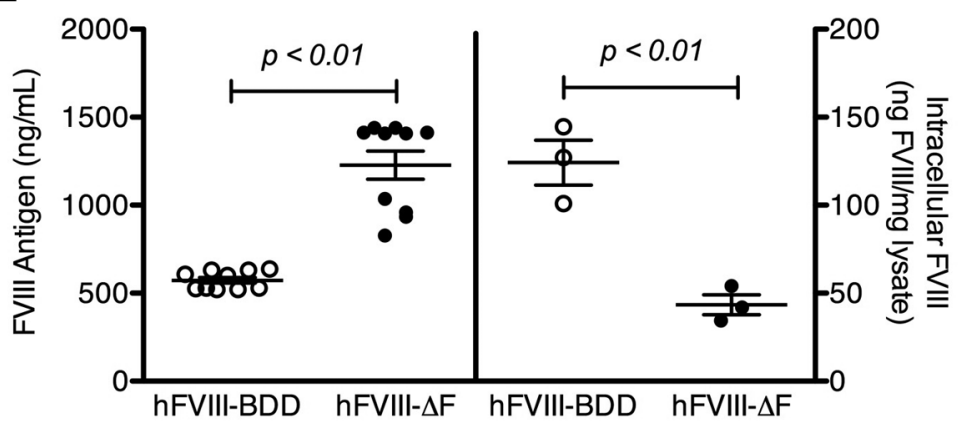

Figure 1. Effect of furin inhibition on the secretion and intracellular retention of human factor VIII (hFVIII) variants. The amount of hFVIII secreted (A and C) or intracellularly retained (B and $\mathbf{D}$ ) from baby hamster kidney (BHK) cells stably expressing either $\mathrm{hFVIII-BDD} \mathrm{(A} \mathrm{and} \mathbf{B})$ or hFVIII- $\triangle \mathrm{F}(\mathbf{C}$ and $\mathbf{D})$ after transduction with vectors containing either the furininhibiting $\alpha 1$-antitrypsin Portland (A1AT-PDX) or a negative control (A1AT-wild type [A1AT-WT] or EGFP). Intracellular FVIII is reported as the relative amount of FVIII after transduction compared with the mean of the EGFP-transduced group. (E) Direct comparison of the amount of secreted (left) and intracellularly retained (right) hFVIII in BHK cells expressing either hFVIII-BDD or hFVIII- $\triangle \mathrm{F}$. All FVIII levels were determined by ELISA in duplicate. Each data point represents a distinct transduction and results are aggregates of 2-4 distinct experiments. Means were compared by 2-tailed Student's $t$ test. $P$ values greater than 0.05 were considered not significant (n.s.). Horizontal markers in whisker plots represent the mean and 1 SEM.

line, a specific inhibitor of furin activity, or a modified FVIII variant designed to avoid furin (FVIII- $\Delta \mathrm{F}$ ). We subsequently utilized FVIII- $\Delta \mathrm{F}$ to study the in vivo relevance of furin processing of FVIII in both murine and canine models of severe HA

Furin activity restricts in vitro hFVIII secretion. $\alpha 1$-Antitrypsin Portland (A1AT-PDX) is a bioengineered serpin whose reactive loop contains the R-X-X-R furin recognition sequence, allowing A1AT-PDX to specifically and irreversibly bind the active site of furin in the nanomolar range (35). In contrast, A1AT-wild type (A1AT-WT) does not interact with furin. AAV serotype 2 (AAV2) vectors encoding A1AT-PDX, A1AT-WT, and EGFP were used to stably transduce baby hamster kidney (BHK) cells expressing hFVIII 


\section{CHO Cells \\ A

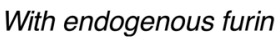

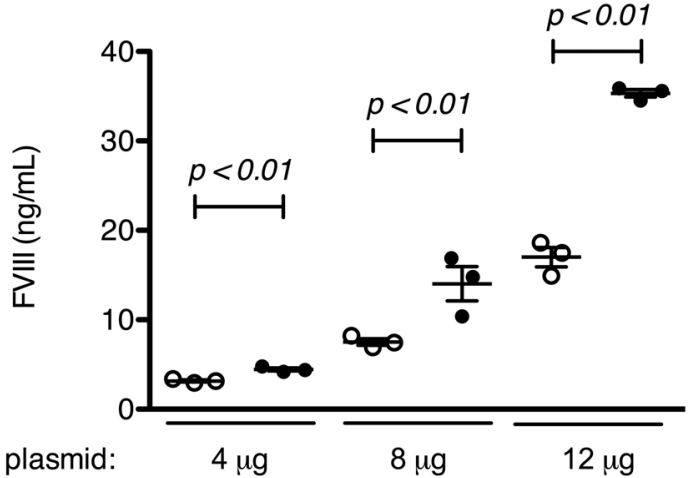

B

LoVo Cells

Without endogenous furin

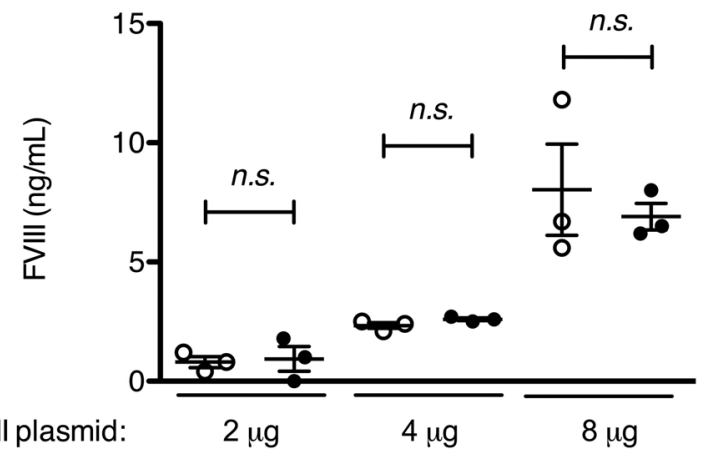

Figure 2. Comparative secretion advantage of human factor VIII- $\Delta \mathrm{F}$ (hFVIII- $\Delta \mathrm{F}$ ) over hFVIII-BDD requires furin. Transient transfection with Lipofectamine 2000 of (A) CHO (furin-expressing) and (B) LoVo (furin-deficient) cells with hFVIII-BDD- (open circles) or hFVIII- $\Delta$ F-containing (closed circles) plasmids at 3 different plasmid amounts, as indicated. FVIII antigen levels were determined 48 hours after transfection and normalized for transfection efficiency. Each data point represents a distinct transfection. Means were compared by 2-tailed Student's $t$ test. $P$ values greater than 0.05 were considered not significant (n.s.). Horizontal markers in whisker plots represent the mean and 1 SEM.

variants to determine the effect of furin inhibition on FVIII. Inhibition of furin by A1AT-PDX both significantly increased hFVIII-BDD secretion and decreased intracellular retention compared with controls (Figure 1, A and B). This result suggests that furin activity impedes FVIII secretion.

We also designed a FVIII variant with the deletion of the 4 amino acids of the R-X-X-R $\downarrow$ furin recognition motif (1645-1648), FVIII- $\Delta \mathrm{F}$, to test if circumventing intracellular furin processing could similarly improve FVIII secretion. Furin inhibition by A1AT-PDX in BHK cells expressing hFVIII- $\Delta \mathrm{F}$ did not change the amount of FVIII that was secreted or intracellularly retained compared with controls (Figure 1, C and D), which indicates that hFVIII- $\Delta \mathrm{F}$ avoids furin processing. We also observed that in BHK cells, significantly more $\mathrm{hFVIII-}-\Delta \mathrm{F}$ was secreted and significantly less was intracellularly retained compared with hFVIII-BDD (Figure 1E). The amount of A1AT variants did not differ between the BHK cell lines (Supplemental Figure 1; supplemental material available online with this article; doi:10.1172/ jci.insight.89371DS1). Recombinant protein yields from BHK clones stably expressing hFVIII- $\Delta \mathrm{F}$ also increased about 3-fold compared with hFVIII-BDD-expressing BHK cells: $210 \mathrm{ng} / \mathrm{cm}^{2} /$ day and $70 \mathrm{ng} /$ $\mathrm{cm}^{2} /$ day, respectively. These results support the hypothesis that furin has a detrimental effect on FVIII$\mathrm{BDD}$ secretion, but that FVIII- $\Delta \mathrm{F}$ escapes this deleterious processing, which leads to increased secretion and decreased intracellular retention.

FVIII- $\Delta \mathrm{F}$ was also secreted significantly better than FVIII-BDD in another cellular model, $\mathrm{CHO}$ (Figure 2A), which, like BHK cells, have endogenous furin. FVIII-BDD- and FVIII- $\Delta \mathrm{F}-$-expressing plasmids, as well as a luciferase reporter gene, were transfected into $\mathrm{CHO}$ cells and the amount of secreted FVIII was quantified relative to the transfection efficiency. The relative amount of secreted FVIII- $\Delta \mathrm{F}$ compared with FVIII-BDD increased with increasing amounts of transfected plasmid. In contrast, in analogous experiments using the unique furin-deficient cell line LoVo (36), FVIII-BDD and FVIII- $\Delta$ F were secreted at identical levels at 3 different plasmid doses (Figure 2B). This result confirms that the increased secretion of FVIII- $\Delta$ F compared with FVIII-BDD from the furin-containing cell lines (BHK, $\mathrm{CHO}$ ) is due to the ability of FVIII- $\Delta \mathrm{F}$ to avoid furin, as FVIII- $\Delta \mathrm{F}$ does not have a comparative advantage in the LoVo cells lacking furin. The comparative advantage of FVIII- $\Delta \mathrm{F}$ over FVIII-BDD increases with increasing FVIII expression, consistent with a larger proportion of expressed FVIII- $\Delta$ F being secreted relative to FVIII-BDD.

Furin processing is critical for hFVIIa and hFIX biological activity. The deleterious effect of furin processing upon FVIII secretion is the converse of other clotting factors in which furin activity is necessary for efficient secretion of biologically functional proteins $(13,15-17)$. As shown in Figure 3, A and B, inhibition of furin by A1AT-PDX decreased FVIIa secretion and activity from human embryonic kidney (HEK) 293 cells. Although inhibition of furin by A1AT-PDX did not change the amount of FIX secreted from HEK293 cells, it did significantly decrease the specific activity of the secreted FIX (Figure 3, C and D). The decreased secretion of functional FIX and FVIIa with the introduction of A1AT-PDX, consistent 


\section{FVlla}

A

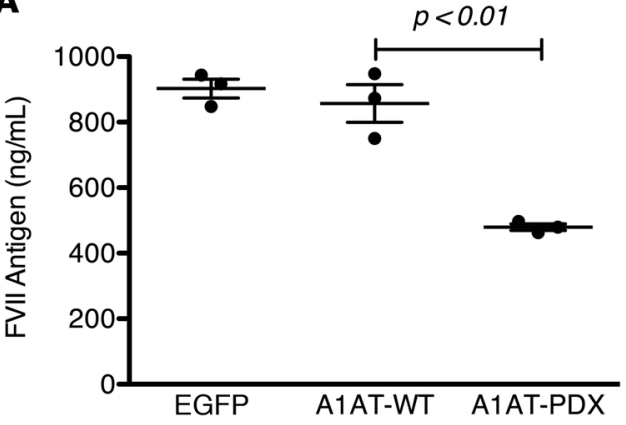

\section{FIX}

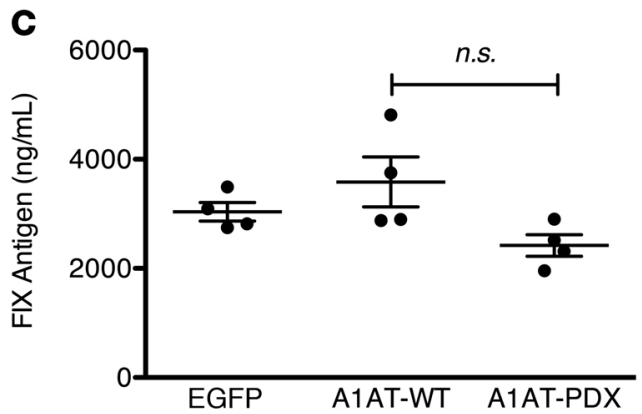

B
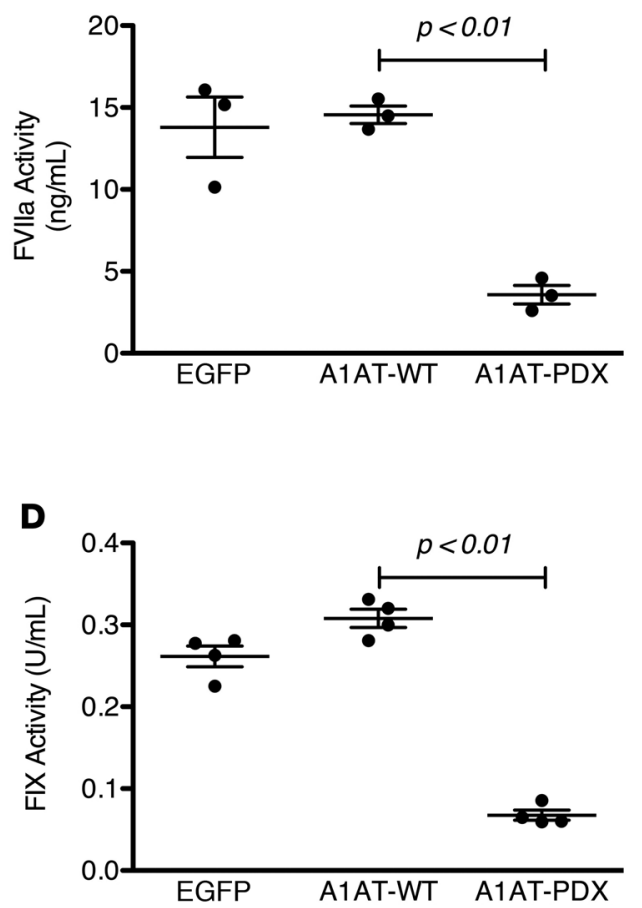

Figure 3. Effect of furin inhibition on the secretion and clotting activity of human factor VIIa (hFVIIa) and hFIX. The amount of factor secreted from either FVIIa- (A) or FIX-producing (C) HEK293 cells after transduction with vectors containing either the furin-inhibiting $\alpha 1$-antitrypsin Portland (A1AT-PDX) or the negative control, A1AT-wild type (A1AT-WT). The amount of FVIla activity (B) or FIX activity (D) from the same conditioned media. Each data point represents a distinct transduction. Means were compared by 2-tailed Student's $t$ test. $P$ values greater than 0.05 were considered not significant (n.s.). Horizontal markers in whisker plots represent the mean and 1 SEM.

with the known supportive role of furin processing of FIX (15) and FVIIa (37), confirms the specific inhibition of furin by A1AT-PDX in these experimental models.

$h F V I I I-\triangle F$ displays increased in vitro and in vivo clotting activity. We also sought to biochemically characterize the furin-evading variant, FVIII- $\Delta$ F. FVIII-BDD is secreted as a combination of SC and heterodimeric species, the latter composed of an HC and LC, as seen by SDS-PAGE analysis (Figure 4A). Only about $20 \%$ of FVIII-BDD is SC, as determined by densitometry (Figure 4B). Cleavage by furin at R-1648 is partially, but not solely, responsible for the formation of the heterodimeric form (12). As expected, over twice as much FVIII- $\Delta$ F remains as SC compared with FVIII-BDD (Figure 4, A and B). Upon activation by thrombin, which includes cleavage of the $\mathrm{N}$-terminal acidic region of $\mathrm{A} 3$, both variants form the identical heterotrimer with equal proportions of A1, A2, and A3-C1-C2, as seen in Figure 4A.

FVIII-BDD and FVIII- $\Delta \mathrm{F}$ also had similar specific activities in a 1-stage activated partial thromboplastin time-based (aPTT-based) clotting assay, in which the purified recombinant procofactor FVIII protein is added to FVIII-deficient plasma, mixed with aPTT reagent, and clotting is initiated by the addition of $\mathrm{CaCl}_{2}$. However, FVIII- $\Delta \mathrm{F}$ exhibited about a 3-fold increased specific activity compared with FVIII-BDD in a 2-stage clotting assay, in which FVIII was activated by excess thrombin prior to being added to the mixture of FVIII-deficient plasma and aPTT reagent (Figure 4C). There was also a modest increase in the halflife of activated FVIII- $\Delta$ F compared with activated FVIII-BDD (2.4 \pm 0.3 minutes vs. $0.91 \pm 0.2$ minutes, respectively), reflecting a slightly slower dissociation of the A2 domain from the heterodimer (Figure 4D). This small difference in A2 stability does not sufficiently account for the 3-fold increased specific activity of FVIII- $\Delta \mathrm{F}$ in the 2-stage clotting assay, as the activated FVIII was added within 0.5 minutes of activation immediately followed by $\mathrm{CaCl}_{2}$. Activated FVIII is subsequently stabilized by its interaction with activated FIX and phospholipids (38). Based on the determined half-lives, the maximal fold difference between the amount of activated FVIII- $\Delta \mathrm{F}$ and activated FVIII-BDD that occurs within the first minute is less than 1.5 and is thus insufficient to account for the 3-fold increase in 2-stage clotting activity of FVIII- $\Delta \mathrm{F}$ compared with FVIII-BDD. We also observed that the 2-stage clotting activity of hFVIII-R1645H was intermediate between hFVIII- $\Delta \mathrm{F}$ and hFVIII-BDD (Supplemental Figure 2).

Given this enhanced in vitro clotting activity, we also determined the in vivo clotting activity of FVIII$\Delta \mathrm{F}$ with 2 distinct hemostatic challenges in severe $\mathrm{HA}$ mice: the tail-clip and ferric chloride $\left(\mathrm{FeCl}_{3}\right)$ assays. These animals have undetectable circulating murine FVIII activity $(<1 \%$ of normal) and have excessive, 

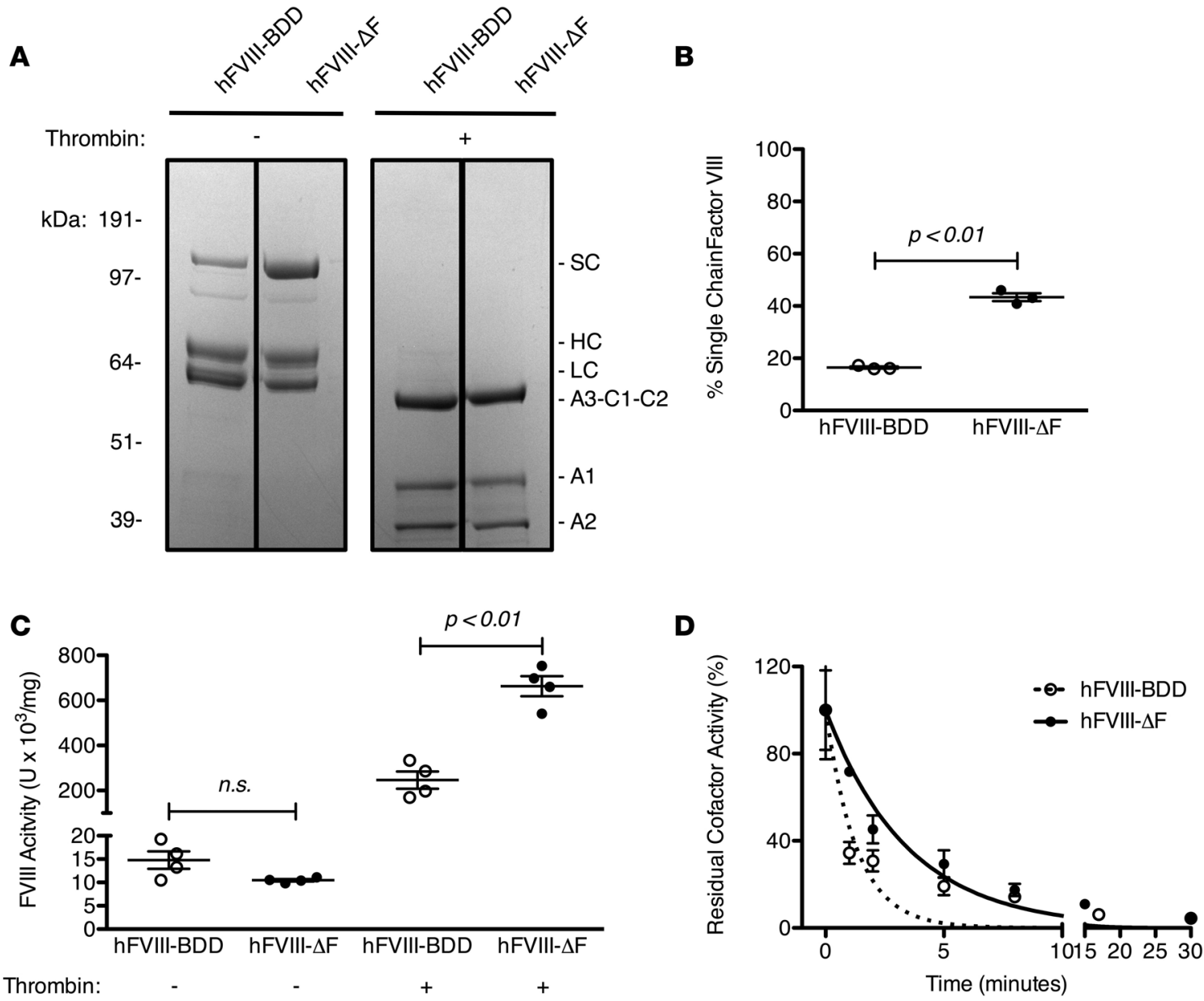

Figure 4. Biochemical characterization of recombinant human factor VIII- $\Delta$ F (hFVIII- $\Delta F)$ compared with hFVIII-BDD. (A) SDS-PACE analysis of $3 \mu \mathrm{g}$ of purified recombinant $\mathrm{hFVIII-BDD}$ and $\mathrm{hFVIII-} \Delta \mathrm{F}$ staining with Coomassie blue before (-) or after (+) activation with $20 \mathrm{nM}$ thrombin. Identified protein species are single chain (SC), heavy chain (HC), and light chain (LC). (B) Quantification of percentage single-chain of each hFVIII variant by densitometric analysis of SDS-PAGE. Each data point represents a distinct measurement. Similar results were obtained with at least 2 distinct protein preparations. (C) hFVIII clotting activity was determined by 1-stage or 2-stage clotting assay. Each data point represents a distinct dilution. Similar results were obtained with at least 2 distinct protein preparations. (D) Decay of activated hFVIII variants following thrombin activation. Residual activity was determined by 2-stage clotting assay and normalized by the 0 time point. Error bars represent SEM of at least 3 separate dilutions. Lines are single-exponential fittings. The half-lives of activated hFVIII- $\Delta \mathrm{F}$ and $\mathrm{hFVIII-BDD}$ are $2.4 \pm 0.3$ minutes $\left(R^{2}=0.96\right)$ and $0.91 \pm 0.2$ minutes $\left(R^{2}=0.91\right)$, respectively. Means were compared by 2 -tailed Student's $t$ test. $P$ values greater than 0.05 were considered not significant (n.s.). Horizontal markers in whisker plots represent the mean and 1 SEM.

often fatal, bleeding in response to trauma, which despite gentle handling, results in shortened life spans, comparable with humans with severe hemophilia without treatment (39). HA mice received $10 \mu \mathrm{g} / \mathrm{kg}$ of either FVIII- $\Delta$ F or FVIII-BDD purified protein immediately prior to both challenges. The FVIII antigen levels were comparable for both variants (about $40 \%$ hemostatically normal) after administration (Supplemental Figure 3). The $10 \mu \mathrm{g} / \mathrm{kg}$ dose was chosen based on our previous data showing that $30 \mu \mathrm{g} / \mathrm{kg}$ of FVIII-BDD protein is required to fully restore hemostasis in the tail-clip model (34) and our in vitro result suggesting that FVIII- $\Delta \mathrm{F}$ has about a 3 -fold increased specific activity compared with FVIII-BDD. As shown in Figure $5 \mathrm{~A}$, FVIII- $\Delta \mathrm{F}$ protein provided superior hemostasis in the tail-clip assay compared with FVIII-BDD protein ( $n=4$ mice/group). Notably, treatment with $10 \mu \mathrm{g} / \mathrm{kg}$ of FVIII- $\Delta$ F limits the blood loss in HA mice to the amount hemostatically normal mice bleed after complete tail transection (34). The same dose of FVIII-BDD did not change the volume of blood loss compared with HA mice that only received buffer. In the $\mathrm{FeCl}_{3}$ carotid injury challenge, HA mice exhibit impaired clot formation and are generally unable to occlude the vessel within 30 minutes (34). In this model, we observed that FVIII- $\Delta$ F protein provided superior clot formation compared with FVIII-BDD protein at a dose of $10 \mu \mathrm{g} / \mathrm{kg}(n \geq 5$ mice/ group, Figure $5 \mathrm{~B}$ ). In both of these models, FVIII- $\Delta \mathrm{F}$ protein provided 2- to 3-fold better in vivo hemostasis than FVIII-BDD, which is consistent with the in vitro result from the 2-stage clotting assay. 
A

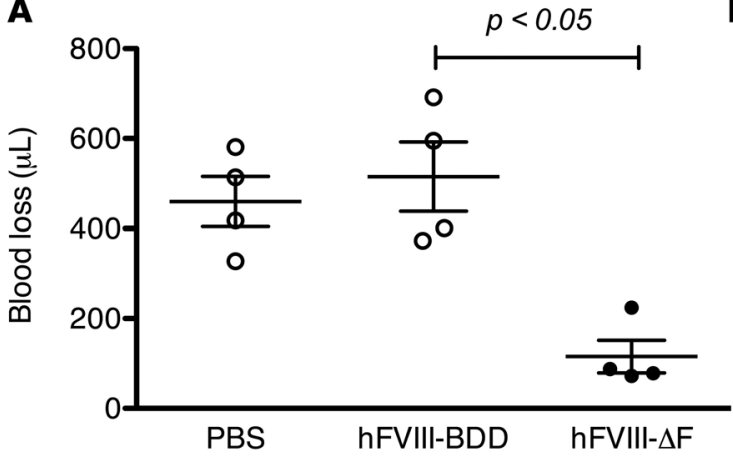

B

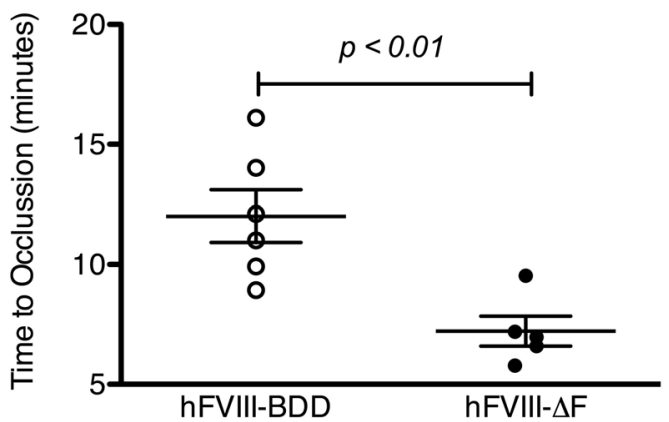

Figure 5. Hemostatic effect of recombinant human factor VIII (hFVIII) variants in severe hemophilia A mice. Mice received PBS or $10 \mu \mathrm{g} / \mathrm{kg}$ recombinant hFVIII protein immediately prior to injury. (A) In the tail-clip challenge, blood loss over 10 minutes was determined after complete tail transection at 3-mm diameter. Median blood loss for mice that received PBS, hFVIII-BDD, and hFVIII- $\Delta$ F was $460 \pm 60,520 \pm 80$, and $120 \pm 40 \mu \mathrm{L}$, respectively. FVIII antigen levels after infusion were similar, as shown in Supplemental Figure 2. (B) In the $\mathrm{FeCl}_{3}$ challenge, time to occlusion of the carotid artery was measured after $7.5 \% \mathrm{FeCl}_{3}$-induced injury. Median time to occlusion for mice that received hFVIII-BDD and hFVIII- $\Delta \mathrm{F}$ was $12 \pm 1$ and $7 \pm 1$ minutes, respectively. Each data point represents an individual animal. Horizontal markers in whisker plots represent the mean and 1 SEM.

Furin circumvention enhances $h F V I I I$ gene transfer in HA mice. To determine if furin processing is also deleterious to FVIII secretion in vivo, AAV serotype 8 (AAV8) vectors encoding hFVIII-BDD or hFVIII$\Delta \mathrm{F}$ under the control of a liver-specific promoter were injected at 3 different doses in severe HA mice. We observed a vector dose-dependent increase in both FVIII antigen and activity (Figure 6, A and B), as expected. At both the mid $\left(8 \times 10^{12}\right.$ vector genome $\left./ \mathrm{kg}[\mathrm{vg} / \mathrm{kg}]\right)$ and high $\left(2 \times 10^{13} \mathrm{vg} / \mathrm{kg}\right)$ dose, there was significantly more circulating FVIII antigen and activity after gene transfer with hFVIII- $\Delta \mathrm{F}$ than $\mathrm{hFVIII-BDD}$. At the high dose, there was over 3 times more hFVIII- $\Delta \mathrm{F}$ circulating than hFVIII-BDD. The increasing advantage of $h F V I I I-\Delta \mathrm{F}$ over $\mathrm{hFVIII-BDD}$ with increasing vector dose is consistent with the results from the cellular studies, in which the benefit of circumventing furin was amplified with increasing FVIII expression. We also observed that the amount of circulating FVIII antigen and activity after gene transfer with hFVIII-R1645H was intermediate between hFVIII- $\Delta \mathrm{F}$ and hFVIII-BDD, in a dose-dependent manner (Supplemental Figure 4).

To determine if this increase in circulating FVIII after gene transfer was due to differences in intracellular protein processing, we measured the hepatic vector gene copy number and mRNA levels (Figure $6, C$ and D) at least 4 weeks after vector delivery. The vector gene copy numbers were similar after gene transfer with hFVIII- $\Delta \mathrm{F}$ and hFVIII-BDD in all dosing cohorts. The hFVIII transcripts were also similar, though there was a small (less than 2-fold) increase in the hFVIII- $\Delta \mathrm{F}$ mRNA compared with hFVIII-BDD mRNA in the highest-dose cohort only; this increase, however, is insufficient to fully account for the larger increase in the circulating protein levels. These results suggest that the higher levels of hFVIII circulating in plasma after $\mathrm{hFVIII}-\Delta \mathrm{F}$ gene transfer compared with hFVIII-BDD are mostly due to enhanced protein secretion and not differences in transduction, although in the high-dose cohort, the increased mRNA may have also contributed. Overall, these in vivo observations are entirely consistent with our in vitro results demonstrating that $\mathrm{hFVIII}-\Delta \mathrm{F}$ is secreted better than $\mathrm{hFVIII-BDD}$, owing to its ability to avoid the negative effects of furin processing. The increased circulating levels of $\mathrm{hFVIII}-\Delta \mathrm{F}$ compared with $\mathrm{hFVIII-BDD}$ suggest that this variant may improve the efficiency of gene therapy for HA.

Furin circumvention enhances $c F$ VIII gene transfer in severe HA dogs without increased immunogenicity. In order to determine the safety and efficacy of FVIII- $\Delta \mathrm{F}$ as a gene therapy strategy for HA, we tested this variant in the canine severe HA model at UNC Chapel Hill. This is a natural disease model that closely mimics the bleeding phenotype of severe HA patients; the canine $F 8$ gene mutation responsible for this model is the same as the disease-causing mutation in $40 \%$ of patients with severe HA (intron 22 inversion) (40). A major limitation of preclinical studies in hemophilia animal models is that most immunocompetent animals will develop antibodies against hFVIII, which complicates the assessment of immunogenicity of novel FVIII variants. The best evaluation of immunogenicity is, thus, the use of species-specific FVIII molecules.

We designed a cFVIII variant with the analogous furin recognition site (H-H-Q-R $\downarrow$ ) deleted, 
A

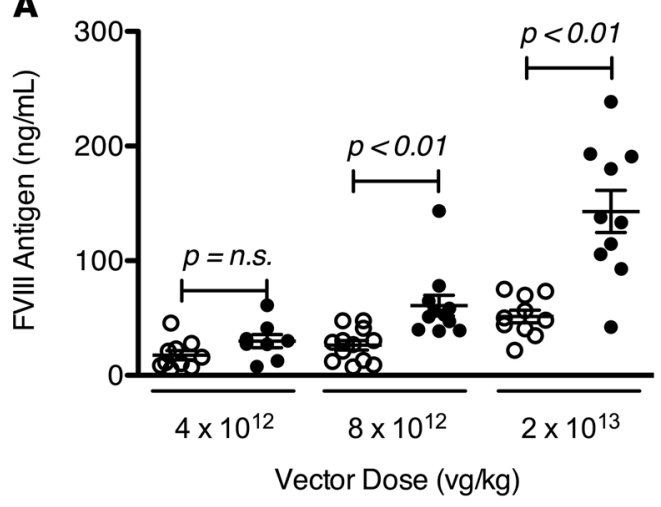

C

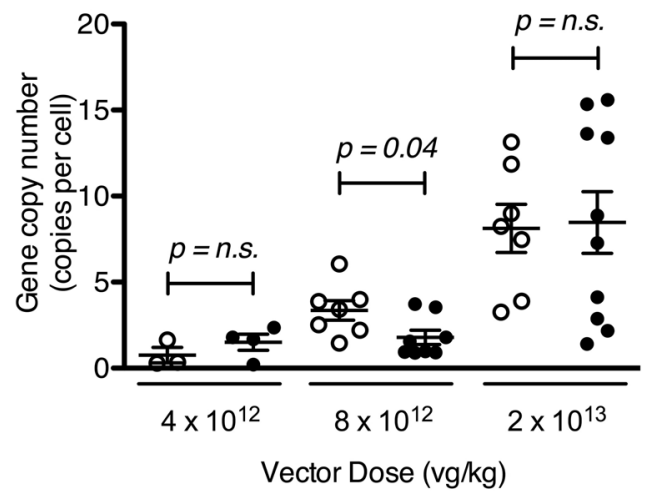

B

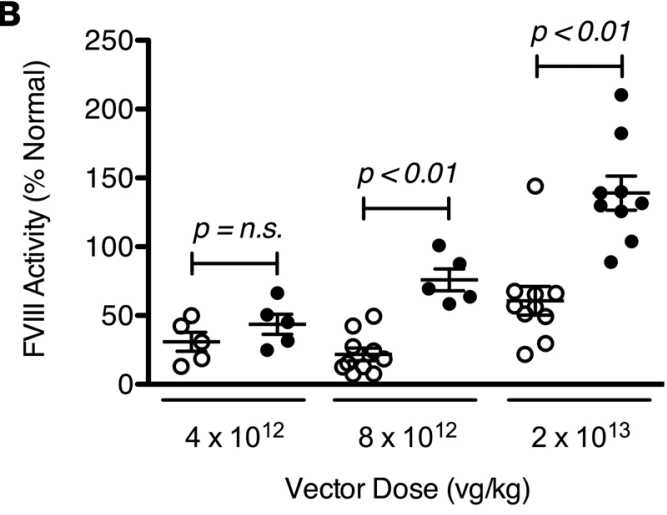

D

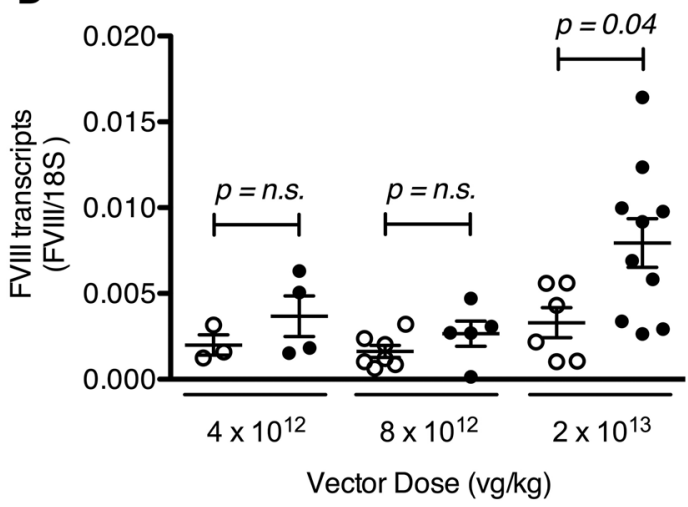

Figure 6. Expression of human factor VIII (hFVIII) variants following adeno-associated viral serotype 8 (AAV8)mediated liver gene transfer in severe hemophilia A (HA) mice. Three dosing cohorts of mice received either AAV8hFVIII- $\triangle \mathrm{F}$ (closed circles) or AAV8-hFVIII-BDD (open circles) with a liver-specific promoter at the indicated vector doses. Circulating FVIII antigen (A) and activity (B), as determined by chromogenic assay, was measured 4-8 weeks after vector infusion. Liver sections were harvested at least 4 weeks after injection and used to determine vector DNA content (C) and mRNA level (D). Each data point represents a single animal. Horizontal markers in whisker plots represent the mean and 1 SEM.

$c F V I I I-\Delta F$. The biochemical characterization of cFVIII- $\Delta \mathrm{F}$ protein is shown in Figure 7 . As we have previously observed, cFVIII-BDD is secreted mostly as the SC form (70\%) (30). cFVIII- $\Delta \mathrm{F}$ and cFVIII-BDD demonstrated similar proportions of the SC and heterodimeric form (Figure 7, A and B), suggesting that removal of the furin recognition motif (amino acids 1645-1648) does not significantly impede the residual cleavage that occurs in the canine orthologs. As we observed for the human orthologs, $c F V I I I-\Delta \mathrm{F}$ and cFVIII-BDD had similar 1-stage clotting activity, but $c F$ VIII- $\Delta \mathrm{F}$ also displayed about a 3-fold increased clotting activity compared with cFVIII-BDD in a 2-stage clotting assay (Figure $7 \mathrm{C}$ ). The half-life of activated $c F V I I I-\Delta \mathrm{F}$ is very similar to the half-life of $c F V I I I-B D D$ (Figure 7D). We also characterized the related FVIII variant in which the canine furin recognition motif (H-H-Q-R $\downarrow$ ) is replaced by the human motif (R-H-Q-R $\downarrow$ ), cFVIII-H1645R (Supplemental Figure 5). cFVIII-H1645R exhibited similar 1-stage clotting activity, but decreased 2-stage activity as compared with cFVIII-BDD. Furthermore, a smaller fraction of cFVIII-H1645R is in the SC form (40\%) compared with cFVIII-BDD (70\%). These results are consistent with the H1645R substitution worsening the deleterious effects of furin processing in cFVIII.

Given our promising gene transfer results in the murine model, we administered AAV8 cFVIII- $\Delta \mathrm{F}$ gene therapy to $2 \mathrm{HA}$ dogs at a total vector dose of $6 \times 10^{12} \mathrm{vg} / \mathrm{kg}$, more than 3-fold less than previously used (5). As shown in Figure 8, A and B, and summarized in Table 2, gene therapy with cFVIII- $\Delta \mathrm{F}$ at this lower vector dose resulted in sustained cFVIII levels of $1.3 \%$ and $2.5 \%$ and whole-blood clotting times (WBCTs) of 16 and 17 minutes, which approach the upper limit of hemostatically normal animals (12 minutes). This therapy resulted in a substantial decrease in the bleeding frequency of each animal such that only 1 combined bleed occurred in the 48 months after gene therapy, which is a $93 \%$ decrease in the expected number 
A

\section{Thrombin:}

kDa: 191-

$97-$

64-

51

39-

c

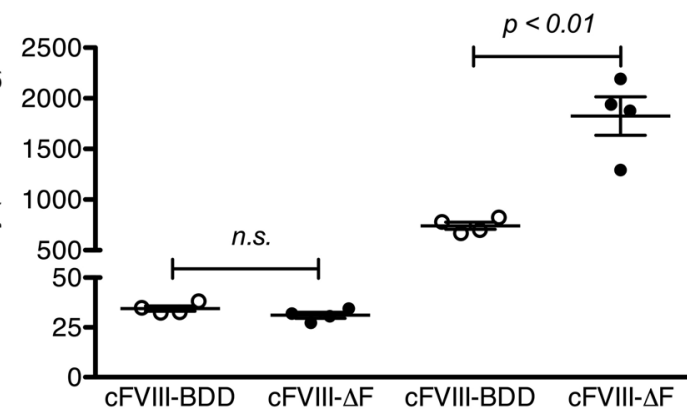

Thrombin:

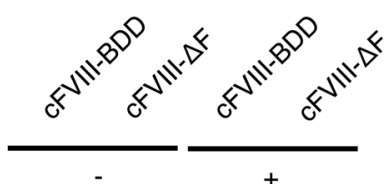

$+$
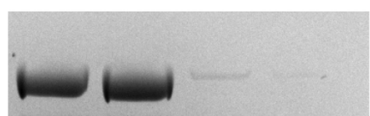

- SC

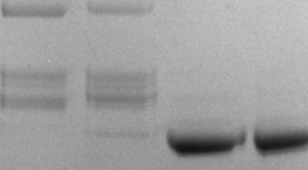

$51-$

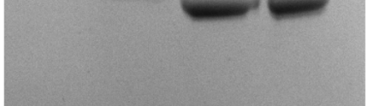

$-\mathrm{HC}$

- LC

- A3-C1-C2

$-A 1$

- A2

\section{B}

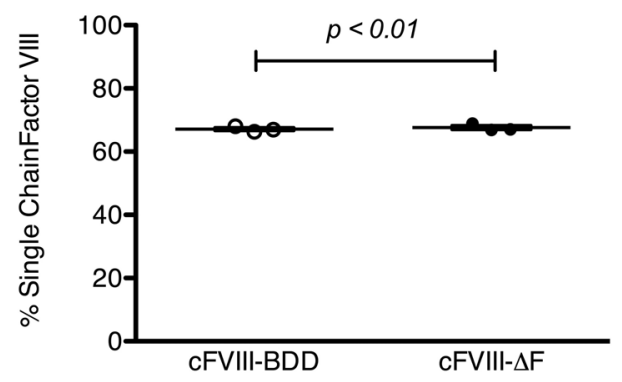

D
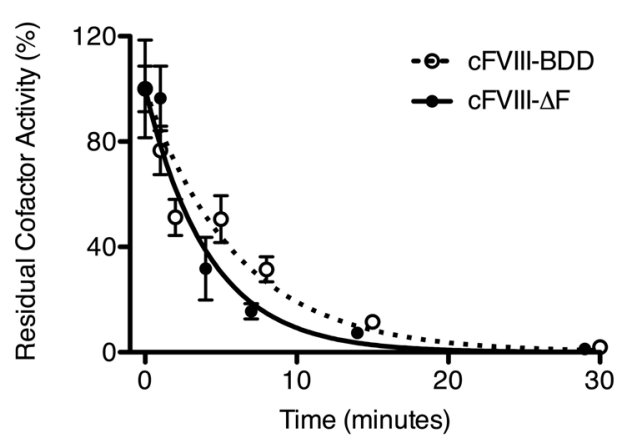

Figure 7. Biochemical characterization of recombinant canine factor VIII- $\Delta \mathrm{F}$ (cFVIII- $\Delta \mathrm{F}$ ) compared with cFVIII-BDD. (A) SDS-PACE analysis of $3 \mu \mathrm{g}$ of cFVIII-BDD and cFVIII- $\Delta$ F staining with Coomassie blue before (-) or after (+) activation with thrombin. Identified protein species are single chain (SC), heavy chain (HC), and light chain (LC). (B) Quantification of percentage of SC of each cFVIII variant by densitometric analysis of SDS-PACE. Each data point represents a distinct measurement. (C) CFVIII clotting activity was determined by 1-stage or 2-stage clotting assay. Each data point represents a distinct dilution. (D) Decay of cFVIII variants following thrombin activation. Error bars represent SEM of at least 3 separate dilutions. Lines are single-exponential fittings. The half-lives of activated cFVIII- $\Delta \mathrm{F}$ and $\mathrm{CFVIII-BDD}$ are $2.2 \pm 0.2$ and $4.7 \pm 0.4$ minutes, respectively; $R^{2}=0.99$ and 0.99 , respectively. Means were compared by 2 -tailed Student's $t$ test. $P$ values greater than 0.05 considered not significant (n.s.). Horizontal markers in whisker plots represent the mean and 1 SEM.

of combined bleeds. The use of $c F V I I I-\Delta F$ transgene AAV8 liver gene therapy resulted in higher sustained FVIII levels, lower WBCT, and more prevented bleeds, compared with previously published data in the same canine HA model where the only difference is the transgene (5), as summarized in Supplemental Table 1. Of note, the canine ortholog of our previously developed hFVIII variant R1645H (34) is analogous to $\mathrm{CFVIII-BDD,} \mathrm{since} \mathrm{histidine} \mathrm{naturally} \mathrm{occurs} \mathrm{in} \mathrm{the} \mathrm{canine} \mathrm{sequence} \mathrm{at} \mathrm{position} 1645$. Thus, the advantage of cFVIII- $\triangle \mathrm{F}$ over cFVIII-BDD for gene therapy in the canine model demonstrates that the complete deletion of the furin recognition site is superior to partial disruption, which is consistent with our data from

Table 2. Summary data of AAV8-cFVIII- $\Delta$ F gene therapy for adult dogs with severe hemophilia A

\begin{tabular}{|c|c|c|c|c|c|c|c|c|}
\hline Dog & Weight (kg) & $\begin{array}{l}\text { Peak cFVIII } \\
\text { Activity (\%) }\end{array}$ & $\begin{array}{l}\text { Plateau cFVIII } \\
\text { Activity }(\%)\end{array}$ & $\begin{array}{l}\text { Plateau WBCTA } \\
\text { (min) }\end{array}$ & $\begin{array}{l}\text { Pre-Therapy Bleeding } \\
\text { Episodes (\#/months) }\end{array}$ & $\begin{array}{l}\text { Post-Therapy Bleeding } \\
\text { Episodes (\#/months) }\end{array}$ & Bethesda Titer & Anti-cFVIII lgG \\
\hline P20 & 30 & 3.7 & $2.5 \pm 0.4$ & $16 \pm 2$ & $7 / 39$ & $0 / 27$ & None & None \\
\hline \multirow[t]{3}{*}{089} & 30 & 1.9 & $1.3 \pm 0.3$ & $17 \pm 2$ & $15 / 38$ & $1 / 21$ & None & None \\
\hline & & & & Total & $22 / 77$ & $1 / 48$ & & \\
\hline & & & & Cumulative & Prevented Bleeds & $93 \%$ & & \\
\hline
\end{tabular}

${ }^{A}$ Mean $\pm S D$. AAV8, adeno-associated viral serotype 8; $c$ FVIII- $\triangle F$, canine factor VIII with furin recognition motif deleted; WBCT, whole-blood clotting time. 
A

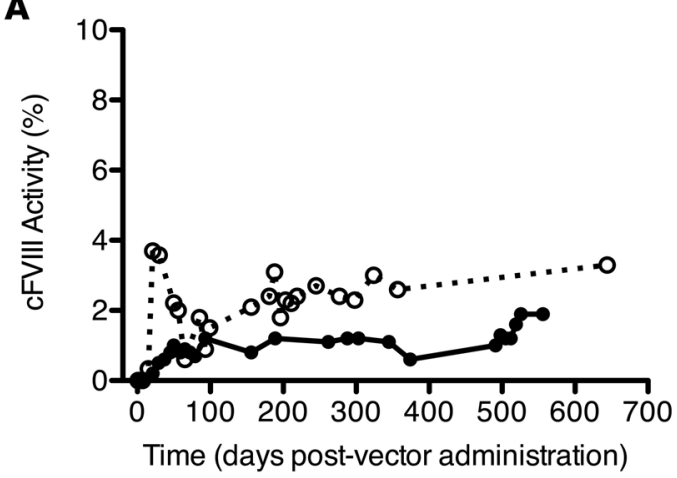

C

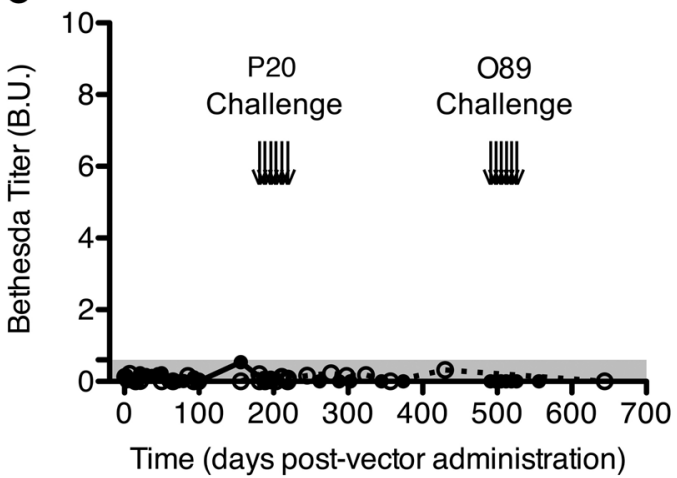

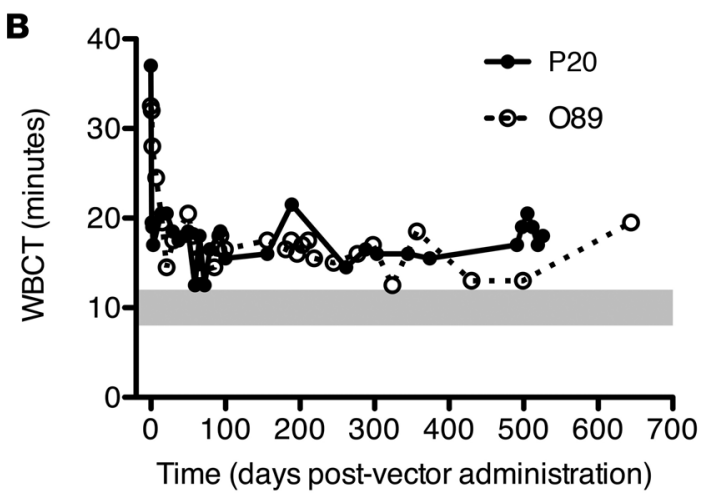

D

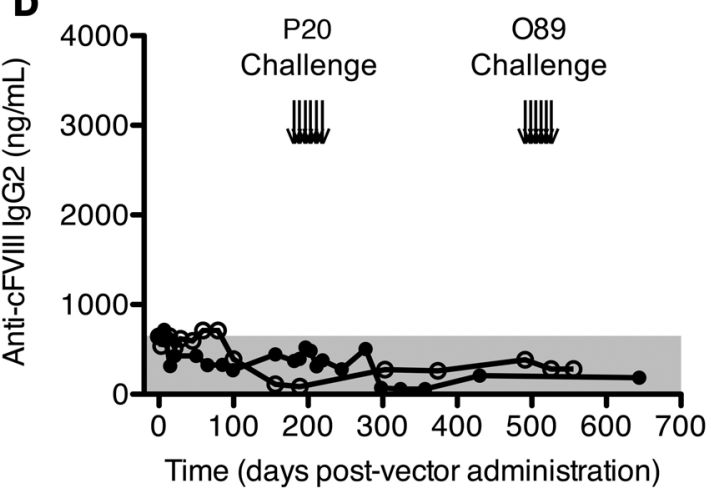

Figure 8. Adeno-associated viral serotype 8 (AAV8)-mediated canine factor VIII- $\Delta F$ (cFVIII- $\Delta F$ ) gene therapy in severe hemophilia A dogs. Two dogs, P2O (closed circles) and 089 (open circles), received $6 \times 10^{12}$ vector genome/ $\mathrm{kg}(\mathrm{vg} / \mathrm{kg}$ ) of AAV8-cFVIII- $\triangle \mathrm{F}$. Time course of cFVIII activity level (A) and whole-blood clotting time (WBCT) (B) for both dogs. Gray bar represents WBCT of dogs without hemophilia. (C) Time course of Bethesda titers for inhibitory antibodies for both dogs. Gray bar represents 0.6 Bethesda unit (B.U.) threshold. (D) Time course of anti-cFVIII IgC2 levels for both dogs. Gray bar represents baseline levels. Arrows in (C) and (D) indicate protein challenges with $2 \mu \mathrm{g} / \mathrm{kg}$ cFVIII-BDD recombinant protein. Each time point run in at least duplicate.

the murine model (Supplemental Figure 4). This enhanced efficiency of cFVIII- $\Delta \mathrm{F}$ gene therapy compared with previous results is consistent with the ability of this variant to circumvent deleterious furin processing, as demonstrated in the in vitro cellular experiments and implied in the mouse studies.

We have also stringently evaluated these animals for evidence of an immune response against cFVIII$\Delta \mathrm{F}$. Neither dog that received gene transfer with $c F V I I I-\Delta F$ developed an inhibitor (an anti-FVIII antibody that neutralizes its procoagulant activity) as determined by Bethesda assay, and neither dog developed non-neutralizing anti-cFVIII antibodies as measured by ELISA assay with over 400 days of observation (Figure 8, C and D). Furthermore, the immune tolerance was maintained despite 6 challenges with purified recombinant cFVIII-BDD protein $(2 \mu \mathrm{g} / \mathrm{kg} /$ challenge). There was also no change in the hepatic and renal function of both dogs, as determined by serum chemistries, nor was there a change in the complete blood counts of either dog.

We further evaluated the immunogenicity of recombinant $c F V I I I-\Delta F$ protein in naive HA dogs. Three additional animals were challenged with 4 intravenous administrations of $2 \mu \mathrm{g} / \mathrm{kg} \mathrm{cFVIII}-\Delta \mathrm{F}$ protein. Again, no animals developed an inhibitor or non-neutralizing anti-cFVIII antibody (Figure 9, A and B), including R13, who belongs to the inhibitor-prone cohort of the UNC HA dog colony (40, 41). The pharmacokinetic parameters of infused $c F V I I I-\Delta F$ protein are similar to the recovery and half-life of cFVIII-BDD (Figure 9C) $(30,40)$. Collectively, data from a total of 5 HA dogs showed a complete lack of an immune response against $c F V I I I-\Delta \mathrm{F}$ as both a gene and protein therapeutic. Together, these results demonstrate that the removal of the 4 amino acids in the residual B-domain do not alter the immunogenicity of FVIII-BDD. FVIII- $\Delta$ F, therefore, has immunogenicity comparable with that of FVIII-BDD, which supports its safety as a therapeutic. 
A

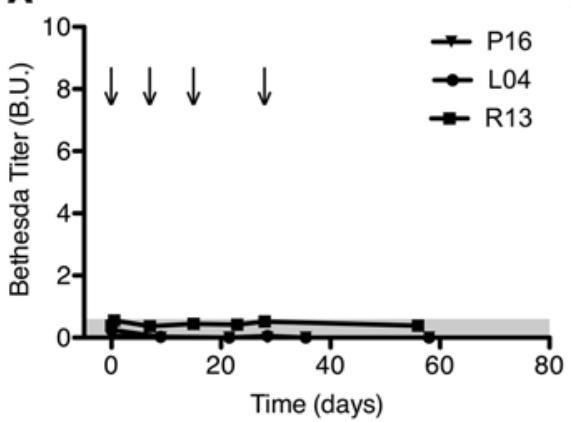

B

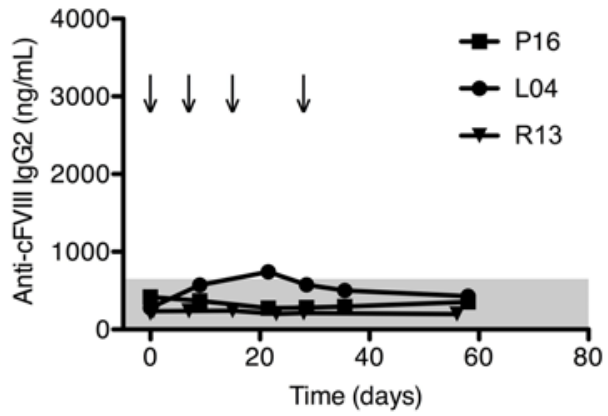

C

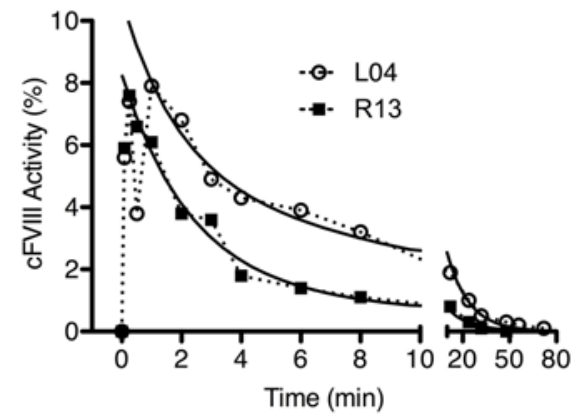

Figure 9. Canine factor VIII- $\Delta \mathbf{F}$ (cFVIII- $\Delta \mathbf{F}$ ) protein therapy in naive severe hemophilia A dogs. (A) Bethesda titers for inhibitory antibodies while receiving $2 \mu \mathrm{g} / \mathrm{kg} \mathrm{cFVIII}-\Delta \mathrm{F}$ protein infusions, as indicated by arrows. Gray bar represents 0.6 Bethesda unit (B.U.) threshold. (B) Anti-cFVIII IgG2 levels of the same dogs. Gray bar represents baseline levels. (C) Time course of cFVIII activity after infusion of $2 \mu \mathrm{g} / \mathrm{kg} \mathrm{cFVIII}-\Delta \mathrm{F}$ protein. Each time point run in at least duplicate. Solid lines are the bi-exponential fitting $\left(R^{2}=0.99\right.$ and 0.98$)$ used to calculate the terminal $(\beta)$ half-lives of 10 and 14 hours.

\section{Discussion}

Over the last 2 decades, FVIII-BDD has demonstrated excellent clinical benefits in safely restoring hemostasis in patients with HA $(23,24)$. There are also emerging promising results from early-phase clinical trials using FVIII-BDD AAV vectors for liver gene therapy (42). The original BDD linker, as well as most of the subsequent modifications, were specifically designed to retain the furin recognition motif comprising amino acids 1645-1648 (Table 1) under the supposition that intracellular processing by furin, including heterodimer formation, is biologically beneficial (26). Indeed, several studies have sought to specifically optimize FVIII heterodimer formation from recombinant expression systems $(29,43,44)$. In this report, we provide the first comprehensive study of the role of furin in FVIII-BDD biology. We observed, contrary to previous assumptions, that furin activity is actually detrimental to FVIII-BDD secretion and procoagulant activity. Herein, we observed that circumventing furin in experimental systems spanning cell culture to large-animal models is in fact advantageous for protein and gene therapies for HA.

Direct specific inhibition of furin significantly increases FVIII-BDD secretion and decreases its intracellular retention from cultured mammalian cell lines. This increase in FVIII-BDD secretion by furin inhibition is opposite what we observed for FVIIa and FIX in the same experimental system, which is consistent with the known supportive role of furin in the cells' secretion of biologically active protein $(15,37)$. Based on these results, we designed a FVIII variant, FVIII- $\Delta \mathrm{F}$, which avoids furin and therefore has increased secretion, compared with FVIII-BDD, in 2 distinct furin-expressing cell lines. These data clarify why previous attempts to optimize FVIII recombinant production with furin overexpression, based on the mistaken assumption that the heterodimer formation was beneficial, actually resulted in lower FVIII levels (44). FVIII- $\Delta$ F does not benefit from furin inhibition, which supports the specific inhibitor we employed. Furin processing has the same deleterious effect on FVIII-BDD secretion in vivo, as demonstrated by the increased circulating FVIII after gene transfer with FVIII- $\Delta \mathrm{F}$ as compared with gene transfer with FVIII-BDD in severe HA mice.

This secretion advantage of FVIII- $\Delta \mathrm{F}$ compared with FVIII-BDD is dependent on functional furin, as both variants have similar secretion from the furin-deficient $\operatorname{LoVo}$ cells $(36,45,46)$. To our knowledge, this is the first direct evidence that furin is the primary proprotein convertase responsible for FVIII-BDD processing, as opposed to other furin-like convertases that share a similar recognition motif. Previous studies have demonstrated that efficient cleavage of the SC FVIII polypeptide into the HC and LC only occurs with B-domain linkers containing amino acids 1645-1648 (R-H-Q-R), or alternatively at least 4 sequential arginine residues (12). This result has been interpreted to implicate furin in the processing of FVIII into the heterodimer, as these observed sequence requirements for efficient SC cleavage satisfy the minimal recognition motif of furin $(13,14)$; however, other ubiquitously expressed furin-like proprotein convertases that share similar recognition motifs, such as PC5/6, PACE4, and PC7, could also contribute $(13,17,47,48)$. PC5/6 and PC7 have recently been suggested to be able to cleave FVIII variants at Arg-1648 in in vitro systems (43). However, these other convertases are still active in LoVo cells $(45,46)$, suggesting that furin is primarily responsible for these observed decreases in FVIII-BDD secretion.

We observed that deleting the 1645-1648 furin recognition motif improved hFVIII-BDD and cFVIII-BDD, 
with both $\mathrm{hFVIII}-\Delta \mathrm{F}$ and $\mathrm{cFVIII}-\Delta \mathrm{F}$, demonstrating (a) similar enhancements in AAV-based gene therapy, and (b) similar increases in 2-stage clotting activity compared with their respective FVIII-BDD orthologs. hFVIII$\Delta \mathrm{F}$ also demonstrates increased in vivo clotting activity compared with $\mathrm{hFVIII-BDD}$ in 2 distinct hemostatic challenges in HA mice.

The biochemical mechanism underlying this enhanced clotting activity is the subject of ongoing research, but several conclusions can be drawn by comparing the effect of removing the 1645-1648 furin recognition motif from hFVIII-BDD and cFVIII-BDD. First, the increased clotting activity is unlikely to be due to differences in A2-domain dissociation. Even though the rate of A2 dissociation in hFVIII-BDD is modestly faster than that in $\mathrm{hFVIII}-\Delta \mathrm{F}$, there is not a substantial difference between the A2-domain dissociation in the canine orthologs. Second, the increased clotting activity is unlikely to be due to increased $\mathrm{SC}$ form. There is no significant difference in the amount of SC or heterodimeric forms between cFVIII- $\Delta \mathrm{F}$ and cFVIII-BDD, though there is in the human orthologs. This observation implies that the deleterious intracellular processing by furin is mediated by a nonproteolytic chaperone role, as has previously been ascribed to furin (49). Isolated SC species of the long-acting FVIII-BDD-Fc fusion protein actually demonstrate 2-stage and in vivo clotting activity comparable with that of the heterodimeric species (50). We speculate that the residual B-domain released after thrombin activation may have a biochemical role in coagulation, as has been observed in FV (51). The FV chimera with its B-domain replaced by the B-domain of FVIII has previously been shown to have decreased specific activity (52).

The deleterious effects of the 1645-1648 furin recognition motif of hFVIII are also reflected in the paucity of HA-causing missense mutations in this region. There is only a single case of a single HA-causing missense mutation within these amino acids: R1645C with a reported FVIII activity of 34\% (53). In contrast, there are multiple cases of multiple missense mutations within the furin recognition motif of FIX causing severe HB (54). The dearth of HA-causing missense mutations in residues 1645-1648 in FVIII, especially in contrast with the frequency of HB-causing mutations within the furin recognition motif of FIX, suggests that disruptions of furin processing of FVIII in vivo do not decrease FVIII biological activity. Rather, our results suggest that such disruptions would likely increase the biological activity.

It is intriguing that furin activity is necessary for FIX biological activity, but likely deleterious for FVIII biological activity. FVIII has the lowest plasma molar concentration of all the coagulation factors and elevated levels of FVIII are associated with thrombotic disease (55-57). These observations imply that hFVIII may have evolved to have limited biological activity. Consistent with this hypothesis, hFVIII is poorly transcribed, translated, and secreted compared with similarly sized proteins, including FV $(7,8,10)$. Ancestral protein reconstruction analysis of FVIII suggests that high-expression sequence determinants within the FVIII sequence have been lost during primate evolution (58). The detrimental role of furin in FVIII-BDD secretion and activity that we report is consistent with the inefficiencies of hFVIII synthesis and intracellular processing, which result in limited hFVIII biological activity. It should be noted that the description of the synthesis and intracellular processing of FVIII has relied on heterologous expression systems. It is unknown if FVIII faces similar difficulties in liver sinusoidal endothelial cells (LSECs), which have recently been identified as the primary source of FVIII synthesis in vivo $(59,60)$.

The observation that furin processing of FVIII-BDD is detrimental for FVIII secretion and clotting activity, and that this deleterious effect can be circumvented by our FVIII- $\Delta \mathrm{F}$ variant in both the human and canine form, has a number of translatable implications. From a safety perspective, our preclinical studies in the canine HA models have demonstrated that FVIII- $\Delta \mathrm{F}$ does not change the immunogenicity of FVIII-BDD as both a gene and protein therapeutic. These safety data are consistent with the empirical observation that most anti-FVIII antibodies are directed against either the A2 or C2 domain $(61,62)$, so modifications in the B-domain were a priori unlikely to increase the immunogenicity, which is the clinical experience with recombinant FVIII-BDD and full-length FVIII exhibiting similar risks of inhibitor development (23-25). Similarly, a new recombinant FVIII-BDD product with only the first half of the 16 amino acids comprising the linker corresponding to the FVIII sequence was recently FDA approved, suggesting there are minimal safety concerns with modifications within the peptide linkers (29). From an efficacy perspective, FVIII- $\Delta \mathrm{F}$ has enhanced hemostatic effectiveness compared with FVIII-BDD in both clotting assays and in vivo challenges. FVIII- $\Delta$ F liver-directed gene therapy has also resulted in a substantial amelioration of the bleeding phenotype in $\mathrm{HA}$ dogs, and FVIII- $\Delta \mathrm{F}$ protein demonstrates typical pharmacokinetics in naive HA dogs. In summary, our preclinical data demonstrate that FVIII- $\Delta \mathrm{F}$ has similar safety, but increased efficacy as compared with FVIII-BDD. 
The enhanced secretion of FVIII- $\Delta$ F compared with FVIII-BDD without compromised immunogenicity and pharmacokinetics offers several advantages for therapeutics for HA. First, the increased secretion of FVIII- $\Delta \mathrm{F}$ increases yields of recombinant protein, which has the potential to decrease production costs of recombinant FVIII-replacement therapy by a similar magnitude. Given the $80 \%$ of hemophilia patients that live in developing countries with little access to effective hemostatic treatments, there are ethical imperatives to create cost-effective therapies to help bridge this treatment gap $(63,64)$. Second, as we have directly demonstrated, FVIII- $\Delta \mathrm{F}$ as a transgene for AAV liver-directed gene therapy substantially increases the circulating FVIII levels in both mice and dogs compared with the FVIII-BDD previously used in similar preclinical studies. A major obstacle for current AAV-based gene therapy is a vector-dose anti-AAV capsid immune response (reviewed in ref. 3); however, the vector dose that demonstrated an amelioration of the bleeding phenotype without an anti-FVIII immune response in our canine studies is similar to the vector dose currently being studied in an ongoing AAV-based gene therapy trial for hemophilia B (NCT00979238) as well as recent AAV liver-directed preclinical studies in nonhuman primates for HA (28).

The canine models have an excellent track record of anticipating the clinical experience of novel therapies for hemophilia (40). They are large outbred animals that exhibit the severe bleeding phenotype including spontaneous bleeds that is the sine qua non of hemophilia. The immunogenicity of novel therapeutics can also be evaluated in a species-specific system $(41,65,66)$. Dose, safety, and efficacy can all be evaluated in the canine model. Our preclinical results utilizing FVIII- $\Delta \mathrm{F}$, therefore, support the translation of furin-avoiding FVIII variants into gene therapy vectors. This variant is amendable to incorporation into other AAV serotype vectors as well as other viral and nonviral gene therapy systems. Circumventing furin is a portable technology that could be combined with other promising FVIII modifications $(28,67)$ to potentially further increase the efficiency of FVIII recombinant expression or gene transfer. Supporting this approach is our observation that the effect of avoiding furin is amplified with increasing FVIII expression in both cellular and in vivo studies. Removing the furin recognition motif could likewise be incorporated into B-domain-substituting linkers to facilitate production of new FVIII products, including long-acting factors. Our 2 related observations - (a) that furin is deleterious to FVIII-BDD biological activity and (b) avoiding furin enhances both protein and gene therapeutics - therefore have the potential to help address the unmet needs of patients with HA worldwide.

\section{Methods}

Cellular studies and production of AAV vectors. A1AT-PDX cDNA was synthesized via site-directed mutagenesis utilizing Agilent's QuickChange II Mutagenesis kit, from A1AT-WT based on the published sequence (35). A1A constructs were cloned into the AAV expression cassette under the control of a cytomegalovirus promoter/enhancer and AAV2 vector was generated by triple transfection and purified with a double cesium chloride gradient (68). Stably transfected BHK cells were utilized as previously reported for production of FVIII variants $(30,34)$. BHK cells were transduced with either AAV2 A1AT-PDX, A1AT-WT, or EGFP at an MOI of 50,000 in serum-free media. Secreted FVIII levels in conditioned media were determined by hFVIII ELISA (Affinity Biological, F8C-EIA). Harvested cell pellets were lysed in Triton X-100 buffer containing HALT Protease Cocktail (ThermoFisher Scientific), subjected to 3 consecutive freeze-thaw cycles, and the resultant supernatant was collected. Total intracellular protein concentration was standardized using a Pierce BCA Protein Assay Kit (ThermoFisher Scientific): ng of hFVIII was divided by mg of total protein. To compare between multiple experiments, FVIII antigen per lysate was normalized by the mean value in the AAV2-EGFP group in every experiment; similar results were obtained analyzing each experiment separately as well. A1AT levels were determined by ELISA as per manufacturer's protocol (Abcam, ab108799).

Human and canine FVIII-BDD cDNAs were used as templates to generate FVIII- $\Delta \mathrm{F}$ cDNA, which was performed by Genscript and verified by sequencing. Transient transfection with Lipofectamine 2000 (Life Technologies) of FVIII-BDD and FVIII- $\triangle \mathrm{F}$ pED (69) was performed with both CHO and LoVo cells, a colon carcinoma cell line. LoVo cells were a gift from Michael S. Marks and Andrei Thomas-Tikhonenko (The Children's Hospital of Philadelphia). FVIII antigen levels were normalized for transfection efficiency using a BioLux Cypridina Luciferase Assay Kit (New England Biolabs): the specific FVIII antigen level was multiplied by the ratio of the relative light unit (RLU) of the specific sample with a reference RLU measured for that experiment. FIX-producing HEK293 cells were similar to those previously generated (66), but utilized a CMV promotor in combination with a posttranscriptional regulatory element of 
woodchuck hepatitis virus (WPRE). FVIIa-producing HEK293 cells were a gift from Paris Margaritas (The Children's Hospital of Philadelphia) as previously generated (37). FIX and FVIIa antigen levels were measured using respective ELISAs (Affinity Biologicals, FIX-EIA and FVII-EIA). FIX activity was calculated using a modified aPTT with recombinant FIX (Benefix, Pfizer) as a standard. FVIIa activity was determined in a modified prothrombin time (PT) assay using NovoSeven (Novo Nordisk) as a standard.

Production and characterization of recombinant FVIII variants. Recombinant FVIII protein was expressed and purified as previously described from stably transfected FVIII-producing BHK cells ( 30 , 34). Stable FVIII-producing BHK clones were established by selecting the $3-5$ highest-FVIII-expressing clones of each variant from more than 48 single colonies after transfection with Lipofectamine 2000 of FVIII-BDD- and FVIII- $\Delta$ F-containing plasmids. Protein purity was assessed by SDS-PAGE analysis. FVIII protein concentration was determined by absorbance at $280 \mathrm{~nm}$ using an extinction coefficient of $1.60 \mathrm{ml} / \mathrm{mg} / \mathrm{cm}$ and a molecular weight of 165,000 Da. Gel electrophoresis band quantification was performed by optical densitometry using Quant software (TotalLab). FVIII activity was determined by 1- or 2-stage aPTT assays and based on known concentrations of FVIII-BDD (ReFacto, Pfizer) (30, 34). Decay of activated FVIII activity was performed as previously described (34). The half-life of the activated FVIII variants was determined by fitting data with a single-exponential decay from $100 \%$ to 0\% using OriginPro (OriginLab) and Prism (GraphPad) software.

Experiments in murine models of HA. Previously, adult HA mice on a C57BL6/129Sv background were crossed with CD4-knockout mice (The Jackson Laboratories) to obtain HA/CD4null mice, which were backcrossed for at least 5 generations. These HA mice were a gift from Haig H. Kazazian (University of Pennsylvania). Severe HA genotype was confirmed and only male mice were utilized for experiments because of the X-linked inheritance of hemophilia as well as the fact that AAV liver gene therapy in females resulted in lower expression levels compared with littermate male mice. Mice received AAV vector or FVIII protein by tail vein injection. FVIII concentrations were determined by ELISA (Affinity Biological, F8CEIA) and FVIII activity was determined by CoaTest SP4 FVIII (Chromogenix) against standards of recombinant hFVIII-BDD.

In vivo hemostasis was determined utilizing 2 distinct challenges: the tail-clip and ferric chloride $\left(\mathrm{FeCl}_{3}\right)$ assays. For the tail-clip challenge, mice were prewarmed at $37^{\circ} \mathrm{C}$, the tail was transected at 3 -mm diameter, and blood was collected for 10 minutes. The total blood loss was determined from the hemoglobin content (70). The $\mathrm{FeCl}_{3}$ assay was performed as previously described $(70,71)$, in which $7.5 \% \mathrm{FeCl}_{3}$ was applied for 2 minutes to the adventitial surface of the carotid artery and the vessel was then washed with saline. Blood flow was monitored by ultrasound.

Mice received AAV8-mediated gene therapy with either FVIII-BDD or FVIII- $\Delta \mathrm{F}$ under the control of a liver-specific promoter, as previously reported (34). Livers were harvested for genomic DNA and RNA isolation at least 4 weeks after vector infusion. cDNA was synthesized using the SuperScript First-strand Synthesis System (Invitrogen), gene copy number was determined by real-time quantitative PCR, and mRNA transcript levels of non-murine FVIII were determined using Taqman or SYBR Green (Applied Biosystems), which was standardized to murine $18 \mathrm{~S}$ ribosomal RNA as applicable. The following primers were used: hFVIII forward, 5'-GGGAAGTTGGAGACACACTGTTG-3'; hFVIII reverse, 5'-TGGCCCATCTTCTACAGTCACTG-3'; fluorescein aminohexylamide-labeled hFVIII probe, 5'-CGGAATCACTGATGTCCGTCCTTTGTATTC-3'; murine 18S forward, 5'-CGCTTCCTTACCTGGTTGAT-3'; and murine 18S reverse, 5'-GAGCGACCAAAGGAACCATA-3'. The amount of FVIII was standardized to serial dilutions of linearized pED expression plasmid containing species-specific FVIII-BDD cDNA.

Experiments in canine models of $H A$. Two HA dogs received AAV8-cFVIII- $\Delta \mathrm{F}$ with a liver-specific promoter via the cephalic vein diluted in PBS over a 30-minute period. Prior to gene therapy, both animals were confirmed to have anti-AAV8 neutralizing antibody titers less than 1:3 (65). WBCT and CFVIII antigen and activity were assayed as previously described (41). Antibodies against cFVIII were previously developed at The Children's Hospital of Philadelphia (30). Neutralizing antibodies against cFVIII were determined by Bethesda assay. Antibodies against cFVIII were measured by ELISA against IgG2 (Bethyl Laboratories, A121P) (41). After gene therapy, dogs were challenged with $2 \mu \mathrm{g} / \mathrm{kg}$ of recombinant cFVIII by intravenous injection. Baseline hematologic, renal, and hepatic function of both dogs was determined before therapy by measuring the white blood cell count, hemoglobin, and platelet count as well as serum electrolytes, creatinine, blood urea nitrogen, creatine phosphokinase, albumin, bilirubin, amylase, lipase, triglycerides, alkaline phosphatase, alanine aminotransferase, and aspartate aminotransferase; these laboratory values 
were again measured after vector infusion and then serially about every 6 months. The recovery and halflife of $c F V I I I-\Delta F$ protein were determined from the time course of FVIII activity after an intravenous injection of $2 \mu \mathrm{g} / \mathrm{kg}$ recombinant canine protein in 2 naive HA dogs. The terminal half-life was determined with biexponential (72) and straight-line fitting of the natural logarithmic values of activity using OriginPro or Prism software, as used previously $(20,30)$.

Study approval. The Children's Hospital of Philadelphia IACUC approved all mouse experiments and The University of North Carolina at Chapel Hill IACUC approved all canine experiments.

Statistics. Means were compared by 2 -sided Student's $t$ test, with $P$ values greater than 0.05 considered nonsignificant (n.s.). Unless otherwise noted, horizontal makers in whisker plots represent the mean and SEM.

\section{Author contributions}

JIS and BSJ planned and executed experiments, conducted data analysis and interpretation, and drafted the manuscript. JMC, RAF, and BJL planned and executed the experiments. EM, RR, and TN carried out canine experiments. SZ provided the AAV vectors. RMC provided insights on experimental design. VRA directed experimental design, conducted data analysis and interpretation, and drafted the manuscript. The authors declare no competing financial interests.

\section{Acknowledgments}

We are thankful to Nicholas Iacobelli for technical assistance. We gratefully acknowledge helpful discussion and editorial comments from Sriram Krishnaswamy and Denise Sabatino. We very much appreciate Michael S. Marks' and Andrei Thomas-Tikhonenko's gift of LoVo cells as well as Paris Margaritas' gift of stable HEK293 cells expressing FVIIa. J.S. received research funding from the American Society of Hematology through the Hematology Opportunities for the Next Generation of Research Scientists. B.S.J. reports receiving Bayer Fellowship Project Award 2015 and a HTRS/Novo Nordisk 2015 Mentored Research Award in Hemophilia or Rare Bleeding Disorders from the Hemostasis and Thrombosis Research Society, Inc., which was supported by Novo Nordisk Inc. T.C.N. reports receiving NIH/NHLBI funding, grant HL63098. V.R.A reports receiving NIH/NHLBI funding, grant P01 HL64190.

Address correspondence to: Valder R. Arruda, The Children's Hospital of Philadelphia, 3501 Civic Center Boulevard, 5056 Colket Translational Research Center, Philadelphia, Pennsylvania 19104, USA. Phone: 215.590.4907; E-mail: arruda@email.chop.edu.

1. Nathwani AC, et al. Long-term safety and efficacy of factor IX gene therapy in hemophilia B. N Engl J Med. 2014;371(21):1994-2004.

2. Nathwani AC, et al. Adenovirus-associated virus vector-mediated gene transfer in hemophilia B. N Engl J Med. 2011;365(25):2357-2365.

3. Arruda VR, Samelson-Jones BJ. Obstacles and future of gene therapy for hemophilia. Expert Opin Orphan Drugs. 2015;3(9):997-1010.

4. Jiang $\mathrm{H}$, et al. Multiyear therapeutic benefit of AAV serotypes 2,6 , and 8 delivering factor VIII to hemophilia A mice and dogs. Blood. 2006;108(1):107-115.

5. Sabatino DE, et al. Efficacy and safety of long-term prophylaxis in severe hemophilia A dogs following liver gene therapy using AAV vectors. Mol Ther. 2011;19(3):442-449.

6. Nichols TC, et al. Protein replacement therapy and gene transfer in canine models of hemophilia A, hemophilia B, von Willebrand disease, and factor VII deficiency. ILAR J. 2009;50(2):144-167.

7. Pipe SW. Functional roles of the factor VIII B domain. Haemophilia. 2009;15(6):1187-1196.

8. Lenting PJ, van Mourik JA, Mertens K. The life cycle of coagulation factor VIII in view of its structure and function. Blood. 1998;92(11):3983-3996.

9. Lai JD, Georgescu MT, Hough C, Lillicrap D. To clear or to fear: An innate perspective on factor VIII immunity. Cell Immunol. 2016;301:82-89.

10. Callaghan MU, et al. Synthesis and Secretion of Coagulation Factor VIII. In: Tanaka K, Davie EW, eds. Recent Advances in Thrombosis and Hemostasis. Springer Japan; 2008:45-67.

11. Pittman DD, Tomkinson KN, Kaufman RJ. Post-translational requirements for functional factor V and factor VIII secretion in mammalian cells. J Biol Chem. 1994;269(25):17329-17337.

12. Lind $\mathrm{P}$, et al. Novel forms of B-domain-deleted recombinant factor VIII molecules. Construction and biochemical characterization. Eur J Biochem. 1995;232(1):19-27.

13. Molloy SS, Thomas G. Furin. In: Dalbey R, Sigman DS eds. The Enzymes Volume XXII: Co- and Posttranslational Proteolysis of Proteins. Cambridge, Massachusetts, USA: Academic Press; 2002:199-235.

14. Couture F, Kwiatkowska A, Dory YL, Day R. Therapeutic uses of furin and its inhibitors: a patent review. Expert Opin Ther Pat. 
2015;25(4):379-396.

15. Wasley LC, Rehemtulla A, Bristol JA, Kaufman RJ. PACE/furin can process the vitamin K-dependent pro-factor IX precursor within the secretory pathway. J Biol Chem. 1993;268(12):8458-8465.

16. Bendetowicz AV, Morris JA, Wise RJ, Gilbert GE, Kaufman RJ. Binding of factor VIII to von Willebrand factor is enabled by cleavage of the von Willebrand factor propeptide and enhanced by formation of disulfide-linked multimers. Blood. 1998;92(2):529-538.

17. Rehemtulla A, Kaufman RJ. Protein processing within the secretory pathway. Curr Opin Biotechnol. 1992;3(5):560-565.

18. White GC, Beebe A, Nielsen B. Recombinant factor IX. Thromb Haemost. 1997;78(1):261-265.

19. Dietrich B, et al. Preclinical safety and efficacy of a new recombinant FIX drug product for treatment of hemophilia B. Int $J$ Hematol. 2013;98(5):525-532.

20. Brinkhous KM, et al. Purified human factor VIII procoagulant protein: comparative hemostatic response after infusions into hemophilic and von Willebrand disease dogs. Proc Natl Acad Sci U S A. 1985;82(24):8752-8756.

21. Toole JJ, Pittman DD, Orr EC, Murtha P, Wasley LC, Kaufman RJ. A large region (approximately equal to $95 \mathrm{kDa}$ ) of human factor VIII is dispensable for in vitro procoagulant activity. Proc Natl Acad Sci U S A. 1986;83(16):5939-5942.

22. Pittman DD, Alderman EM, Tomkinson KN, Wang JH, Giles AR, Kaufman RJ. Biochemical, immunological, and in vivo functional characterization of B-domain-deleted factor VIII. Blood. 1993;81(11):2925-2935.

23. Berntorp E. Introduction. Semin Hematol. 2001;38(2 Suppl 4):1-3.

24. Recht M, et al. Clinical evaluation of moroctocog alfa (AF-CC), a new generation of B-domain deleted recombinant factor VIII (BDDrFVIII) for treatment of haemophilia A: demonstration of safety, efficacy, and pharmacokinetic equivalence to full-length recombinant factor VIII. Haemophilia. 2009;15(4):869-880.

25. Gouw SC, et al. Factor VIII products and inhibitor development in severe hemophilia A. N Engl J Med. 2013;368(3):231-239.

26. Sandberg H, et al. Structural and functional characteristics of the B-domain-deleted recombinant factor VIII protein, r-VIII SQ. Thromb Haemost. 2001;85(1):93-100.

27. Thim L, et al. Purification and characterization of a new recombinant factor VIII (N8). Haemophilia. 2010;16(2):349-359.

28. McIntosh J, et al. Therapeutic levels of FVIII following a single peripheral vein administration of rAAV vector encoding a novel human factor VIII variant. Blood. 2013;121(17):3335-3344.

29. Sandberg H, et al. Functional characteristics of the novel, human-derived recombinant FVIII protein product, human-cl rhFVIII. Thromb Res. 2012;130(5):808-817.

30. Sabatino DE, et al. Recombinant canine B-domain-deleted FVIII exhibits high specific activity and is safe in the canine hemophilia A model. Blood. 2009;114(20):4562-4565.

31. Doering C, Parker ET, Healey JF, Craddock HN, Barrow RT, Lollar P. Expression and characterization of recombinant murine factor VIII. Thromb Haemost. 2002;88(3):450-458.

32. Doering CB, Healey JF, Parker ET, Barrow RT, Lollar P. High level expression of recombinant porcine coagulation factor VIII. J Biol Chem. 2002;277(41):38345-38349.

33. Zakas PM, Gangadharan B, Almeida-Porada G, Porada CD, Spencer HT, Doering CB. Development and characterization of recombinant ovine coagulation factor VIII. PLoS One. 2012;7(11):e49481.

34. Siner JI, et al. Minimal modification in the factor VIII B-domain sequence ameliorates the murine hemophilia A phenotype. Blood. 2013;121(21):4396-4403.

35. Jean F, et al. alpha1-Antitrypsin Portland, a bioengineered serpin highly selective for furin: application as an antipathogenic agent. Proc Natl Acad Sci U S A. 1998;95(13):7293-7298.

36. Takahashi S, et al. A second mutant allele of furin in the processing-incompetent cell line, LoVo. Evidence for involvement of the homo B domain in autocatalytic activation. J Biol Chem. 1995;270(44):26565-26569.

37. Margaritis P, Arruda VR, Aljamali M, Camire RM, Schlachterman A, High KA. Novel therapeutic approach for hemophilia using gene delivery of an engineered secreted activated Factor VII. J Clin Invest. 2004;113(7):1025-1031.

38. Fay PJ, Beattie TL, Regan LM, O'Brien LM, Kaufman RJ. Model for the factor VIIIa-dependent decay of the intrinsic factor Xase. Role of subunit dissociation and factor IXa-catalyzed proteolysis. J Biol Chem. 1996;271(11):6027-6032.

39. Staber JM, Pollpeter MJ. Shortened lifespan and lethal hemorrhage in a hemophilia A mouse model. PLoS One. 2016;11(5):e0154857.

40. Nichols TC, Hough C, Agersø H, Ezban M, Lillicrap D. Canine models of inherited bleeding disorders in the development of coagulation assays, novel protein replacement and gene therapies. J Thromb Haemost. 2016;14(5):894-905.

41. Finn JD, et al. Eradication of neutralizing antibodies to factor VIII in canine hemophilia A after liver gene therapy. Blood. 2010;116(26):5842-5848.

42. Press Releases. BioMarin. http://investors.bmrn.com/releases.cfm. Accessed September 1, 2016

43. Demasi MA, de S Molina E, Bowman-Colin C, Lojudice FH, Muras A, Sogayar MC. Enhanced proteolytic processing of recombinant human coagulation factor VIII B-domain variants by recombinant furins. Mol Biotechnol. 2016;58(6):404-414

44. Plantier JL, et al. B-domain deleted factor VIII is aggregated and degraded through proteasomal and lysosomal pathways. Thromb Haemost. 2005;93(5):824-832.

45. Miranda L, Wolf J, Pichuantes S, Duke R, Franzusoff A. Isolation of the human PC6 gene encoding the putative host protease for HIV-1 gp160 processing in CD4+ T lymphocytes. Proc Natl Acad Sci U S A. 1996;93(15):7695-7700.

46. Seidah NG, et al. cDNA structure, tissue distribution, and chromosomal localization of rat PC7, a novel mammalian proprotein convertase closest to yeast kexin-like proteinases. Proc Natl Acad Sci U S A. 1996;93(8):3388-3393.

47. Seidah NG, Prat A. The biology and therapeutic targeting of the proprotein convertases. Nat Rev Drug Discov. 2012;11(5):367-383.

48. Seidah NG, Sadr MS, Chrétien M, Mbikay M. The multifaceted proprotein convertases: their unique, redundant, complementary, and opposite functions. J Biol Chem. 2013;288(30):21473-21481.

49. Pavlaki M, Zucker S, Dufour A, Calabrese N, Bahou W, Cao J. Furin functions as a nonproteolytic chaperone for matrix metalloproteinase-28: MMP-28 propeptide sequence requirement. Biochem Res Int. 2011;2011:630319.

50. Buyue Y, et al. A single chain variant of factor VIII FC fusion protein retains normal in vivo efficacy but exhibits altered in vitro 
activity. PLoS One. 2014;9(11):e113600.

51. Bunce MW, Bos MH, Krishnaswamy S, Camire RM. Restoring the procofactor state of factor Va-like variants by complementation with B-domain peptides. J Biol Chem. 2013;288(42):30151-30160.

52. Pittman DD, Marquette KA, Kaufman RJ. Role of the B domain for factor VIII and factor V expression and function. Blood. 1994;84(12):4214-4225.

53. Eckhardt CL, et al. Factor VIII gene (F8) mutation and risk of inhibitor development in nonsevere hemophilia A. Blood. 2013;122(11):1954-1962.

54. Rallapalli PM, Kemball-Cook G, Tuddenham EG, Gomez K, Perkins SJ. An interactive mutation database for human coagulation factor IX provides novel insights into the phenotypes and genetics of hemophilia B. J Thromb Haemost. 2013;11(7):1329-1340.

55. Koster T, Blann AD, Briët E, Vandenbroucke JP, Rosendaal FR. Role of clotting factor VIII in effect of von Willebrand factor on occurrence of deep-vein thrombosis. Lancet. 1995;345(8943):152-155.

56. Rosendaal FR. High levels of factor VIII and venous thrombosis. Thromb Haemost. 2000;83(1):1-2.

57. Kyrle PA, et al. High plasma levels of factor VIII and the risk of recurrent venous thromboembolism. NEngl J Med. 2000;343(7):457-462.

58. Zakas P, Knight K, Parker ET, Spencer HT, Gaucher E, Doering CB. Bioengineering coagulation factor VIII through ancestral protein reconstruction. Blood. 2015;126(23):123.

59. Fahs SA, Hille MT, Shi Q, Weiler H, Montgomery RR. A conditional knockout mouse model reveals endothelial cells as the principal and possibly exclusive source of plasma factor VIII. Blood. 2014;123(24):3706-3713.

60. Everett LA, Cleuren AC, Khoriaty RN, Ginsburg D. Murine coagulation factor VIII is synthesized in endothelial cells. Blood. 2014;123(24):3697-3705.

61. Prescott R, et al. The inhibitor antibody response is more complex in hemophilia A patients than in most nonhemophiliacs with factor VIII autoantibodies. Recombinate and Kogenate Study Groups. Blood. 1997;89(10):3663-3671.

62. Lollar P. Pathogenic antibodies to coagulation factors. Part one: factor VIII and factor IX. J Thromb Haemost. 2004;2(7):1082-1095.

63. Hough C, Lillicrap D. Gene therapy for hemophilia: an imperative to succeed. J Thromb Haemost. 2005;3(6):1195-1205.

64. Skinner MW. WFH: closing the global gap--achieving optimal care. Haemophilia. 2012;18 Suppl 4:1-12

65. Callan MB, Haskins ME, Wang P, Zhou S, High KA, Arruda VR. Successful phenotype improvement following gene therapy for severe hemophilia A in privately owned dogs. PLoS ONE. 2016;11(3):e0151800.

66. Crudele JM, et al. AAV liver expression of FIX-Padua prevents and eradicates FIX inhibitor without increasing thrombogenic ity in hemophilia B dogs and mice. Blood. 2015;125(10):1553-1561.

67. Doering CB, et al. Directed engineering of a high-expression chimeric transgene as a strategy for gene therapy of hemophilia $\mathrm{A}$. Mol Ther. 2009;17(7):1145-1154.

68. Arruda VR, et al. Peripheral transvenular delivery of adeno-associated viral vectors to skeletal muscle as a novel therapy for hemophilia B. Blood. 2010;115(23):4678-4688.

69. Kaufman RJ, Davies MV, Wasley LC, Michnick D. Improved vectors for stable expression of foreign genes in mammalian cells by use of the untranslated leader sequence from EMC virus. Nucleic Acids Res. 1991;19(16):4485-4490.

70. Ivanciu L, et al. A zymogen-like factor Xa variant corrects the coagulation defect in hemophilia. Nat Biotechnol. 2011;29(11):1028-1033.

71. Schlachterman A, et al. Factor V Leiden improves in vivo hemostasis in murine hemophilia models. J Thromb Haemost. 2005;3(12):2730-2737.

72. Lee M, Morfini M, Negrier C, Chamouard V. The pharmacokinetics of coagulation factors. Haemophilia. 2006;12 Suppl 3:1-7.

73. Doering CB, Healey JF, Parker ET, Barrow RT, Lollar P. High level expression of recombinant porcine coagulation factor VIII. J Biol Chem. 2002;277(41):38345-38349. 